\title{
Subjective and Objective Measures of Streetscape Perceptions: Relationships with Property Value in Shanghai
}

\author{
Waishan Qiu ${ }^{1, *}$, Wenjing Li $^{2}$, Ziye Zhang ${ }^{3}$, Xiaojiang Li $^{4}$, Xun Liu ${ }^{5}$, Xiaokai Huang ${ }^{6}$ \\ ${ }^{1}$ Department of City and Regional Planning, Cornell University, Ithaca, NY, USA, qiuwaishan@126.com \\ ${ }^{2}$ Center for Spatial Information Science, The University of Tokyo, Tokyo, Japan, liwenjing@csis.u-tokyo.ac.jp \\ ${ }^{3}$ Cornell Institute for China Economic Research, Cornell University, Ithaca, NY, USA, zz396@cornell.edu \\ ${ }^{4}$ Temple University, Philadelphia, PA, USA, lixiangjiang.gis@gmail.com \\ ${ }^{5}$ University of Virginia, Charlottesville, VA, USA, x14xw@virginia.edu \\ ${ }^{6}$ Graduate School of Design, Harvard University, Cambridge, MA, USA, tjuhxk@gmail.com \\ ${ }^{*}$ Correspondence: qiuwaishan@126.com (W.Qiu.)
}

\begin{abstract}
The relationship between the street environment and the health, education, mobility, and criminal behaviors of its citizens has long been investigated by economists, sociologists, and urban planners. Homebuyers were found to pay a premium for a better street appearance. Prior studies considering streetscapes mainly focus on objective measures such as the number of nearby trees, the tree canopy area, or the view index of physical features such as greenery, sky or building. However, human perceptions have complex relationships to physical features. Prior studies that relied on counting individual physical features or simply recombining them do not fully capture the comprehensive human perception. In contrast, this study proposed a new approach for the urbanscale application to quantify both subjectively and objectively measured streetscape scores for six important perception qualities, namely Greenness, Walkability, Safety, Imageability, Enclosure, and Complexity. Built on prior studies in measuring urban design quality, and with emerging applications in urban perceptions using deep learning and open-source street view imagery, we (1) effectively collected and evaluated both subjectively and objectively- measured perceptions; (2) investigate the coherence and divergence in ML-predicted subjective scores and formula-derived objective scores; and (3) compare their effects in affecting house prices taking Shanghai as a case study using a large-scale dataset on home transactions. The results implied: first, the percentage increase in sales price attributable to street scores is significant for both subjective and objective measurements. In general subjective scores explained more variance over structural attributes and objective scores in the hedonic price model. Particularly, objective Greenness, subjective Safety, and Imageability scores positively affected house prices. Second, for Greenness and Imageability scores, the subjective and objective measures exhibited opposite signs in affecting house prices, which implied that there might be mechanisms related to the psychological, social-demographical characteristics of street users that have not been fully incorporated by objective measures that taking view indices or recombination of them. In addition, certain objective measures might outperform the subjective counterparts when the connotation of the perception is self-evident and not complicated, for example, the Greenness. For those concepts that were not familiar to the average person, a subjective framework exhibits better performance. This is the first study comprehensively expanding the hedonic price method with both subjectively and objectively measured streetscape qualities. It suggested that city authorities could levy a street environment tax to compensate the public budget invested in street environments where developers secured benefits from a price premium. This study enriches our understanding of the economic values of the subjective and
\end{abstract}


objective measures street qualities. It sheds light on promising future study areas where the coherence and divergence of the two measurements should be further stressed.

Keywords: street view image; subjective and objective perceptions; housing prices; machine learning; computer vision

\section{Introduction}

\subsection{Street Environment and Property Values}

Urban street is a vital medium for urban residents to thrive- its perceptual quality has significant impacts on residents' behaviors and quality of life (Dubey et al., 2016). On the one hand, physical disorder with the street (e.g., broken windows, abandoned housings, graffiti, and decayed street lighting) correlates to crime, decreases resident's sense of safety, and consequently lowers residents' willingness to live (He et al., 2017; Naik et al., 2014a). On the other hand, well-designed and maintained street environment increases residents' physical activities, lessen their stress, improve their health (Brownson et al., 2004; Jackson, 2003) and perceived safety (Dubey et al., 2016). Streetscapes also affect pedestrians' route choices (Salazar Miranda et al., 2021), perceived thermal comfort and walking comfort (Zeng et al., 2018). Therefore, better understanding of perceptual qualities of street environment can help cities to improve public health and sustainability (Fu et al., 2019).

Street environment have also been revealed to have impacts on house prices. (Anderson \& West, 2006; Chen et al., 2020; Fu et al., 2019; Orland et al., 1992; Y. Zhang \& Dong, 2018). A study of Hong Kong indicated that poor street views decreased property values (Jim \& Chen, 2009). In this regard, Hedonic Price Model (HPM) has been widely applied to quantitatively reveal to what extent the street environment affect house prices along with other neighborhood, location, and structure characteristics (Cavailhès et al., 2008; Rosen, 1974; Ye et al., 2019; Y. Zhang \& Dong, 2018). Street environment can be measured subjectively, objectively or in combination (Lin \& Moudon, 2010; Nyunt et al., 2015). In general, subjectively-measured perceptions of environment are self-reported from survey questionnaires (Wilbur et al.,2003; Humpel et 1.,2004b), while objectively-measured counterparts usually come from field data collection (Hoehner etal.,2005; de Vries et al., 2007) or land use data available in Geographical Information System (GIS) (Lee and Moudon, 2006). However, prior housing price studies often captured the influence of street environment through the test of fixed effect of neighborhood or location variables such as zip codes. More micro-scale and human-centered perceptual qualities have been often omitted. In particular, there exists at least three knowledge gaps.

\subsection{Knowledge Gap}

First, the extent to which subjective and objective perceptions of the street environment complement or overlap each other in influencing property values has not been stressed enough in HPM literature. No prior study has systemically investigated the associations of both subjectively and objectively measured streetscape perception in house prices studies. Prior studies investigated the effects of the two measures at the same time were concentrated in walking for health (Lin \& Moudon, 2010; Nyunt et al., 2015) or urban design studies (Ewing \& Handy, 2009; Ma et al., 2021; Qiu et al., 2019; F. Zhang et al., 2018). Moreover, they often indicated poor agreements between the impact of objective and subjective measures (Lee \& Moudon, 2006). 
Second, prior studies of street environment and house prices focused on the objective measures and took physical features such as street greenery and sky view as perception indicators (Chen et al., 2020; Fu et al., 2019; Ye et al., 2019; Y. Zhang \& Dong, 2018). Few studies have addressed the impact of subjectively-measured street perceptions (such as safety and imageability) on surrounding housing prices.

Third, even within the literature of objective measures, a comprehensive and eye-level street perception have not been addressed enough. On the one hand, only very few physical features (such as the greenery, sky, and building) have been investigated individually, while other important visual elements such as street furniture, building façade, pedestrians, commercial signs have not been incorporated into the housing price models. Additionally, only individual impact has been tested while the collective effect of these elements were left behind. On the other hand, limited by the data availability of urban scene perceptions, prior objective measures relied on land use, remote sensing or aerial imagery datasets in GIS. They often took the acreage of, distance to, or accessibility to the aforementioned amenities (e.g., parks and plazas, green areas, lakes) as indices which did not capture eye-level perceptions.

\subsection{Contribution}

In short, neither the objective measures nor the subjective measures of street scene perceptions have been stressed adequately in housing price studies. Although the differences between subjective and objective measures of the street environment has been a popular topic in walking and health studies; for HPM literature, the extent to which objective and subjective measures overlap or complement each other in influencing the residents' willingness to pay and property values has never been stressed adequately. Implied by prior studies, (1) more subtle visual characteristics such as the texture of buildings, sculptures, and materials, (2) the aesthetics of the streetscape, and (3) their effect on pedestrians' perceptions need to be stressed to advance explore the preferences, demands, and willingness to pay of residents for public space (Fu et al., 2019).

The contribution of this study is fourfold. First, we enrich urban design quality measures literature with a scalable, automated, and high-throughput framework using online survey, opensource SVI, and deep learning. The framework achieves efficient and accurate measures of both the objective and subjective perceptual qualities of the eye-level street environment. Second, we fill in the gap between the subjective measured perceived assessment of street environment qualities and surrounding property value. Most prior research only focused on the impact of objectively measured streetscape qualities from physical features; however, physical features individually do not necessarily capture human perceptions. Third, we enrich the objective measures of street environment and housing price literature by utilizing more comprehensive street feature indices than prior studies (which relied on no more than three individual features such as greenery or sky or building view). Fourth, to what extent subjective and objective environmental measures are complement or conflicting each other is never clearly stated. One study showed that compared with subjective measures, objective measures of the urban environment showed more significant relationships with pedestrian's behaviors (Lin \& Moudon, 2010). Another studies show that subjective and objective measures are non-overlapping measures complementing each other in providing information on built environment characteristics (Nyunt et al., 2015). We contrast the subjective scores predicted with objective perception measures and report the divergence and coherence between these two types of indicators on property value.

The proposed framework is automated, high-throughput and scalable to utilize deep learning and SVI to measure both subjective and objective perceptions of street qualities from eye-level. With a comprehensive investigation into the relationship between streetscape perceptions and property 
values, this study provides a scientific basis for policy makers, planners, and real estate developers to adequately address the economic value of street environments. It is also an applicable tool for formulating street design and maintenance policy and studying housing price characteristics.

\section{Related Works}

\subsection{Conventional street environment measures in HPM studies}

Take the most measured feature- street greenery as an example, they are often measured using indicators that were not human-perception-centered, such as the numbers of trees fronted the property (Donovan \& Butry, 2010), the size of tree canopy (Pandit et al., 2014), the percentage of ground cover (Laverne \& Winson-Geideman, 2003), or the distance to large green areas (H. Kim \& Carruthers, 2015). While the literature in street greenery and housing price have been well developed, only several explored the effects of other individual visual element, for instance street lighting (Willis et al., 2005), open space (Anderson \& West, 2006), and ground traffic (Larsen \& Blair, 2014). However, traditional indicators such as tree canopy cover cannot fully incorporate the human eye-level perceived streetscape due to the large variance in the field and direction of view (Li et al., 2015; Yang et al., 2009; Y. Zhang \& Dong, 2018). Additionally, objectively measured visual elements alone failed to comprehensively represent residents' experiences on the street (Ewing \& Handy, 2009).

\subsection{Eye-Level Street Perceptions}

More recently, with deep learning and publicly-available geo-referenced street view imagery (SVI), emerging studies started to apply semantic segmentation to extract the pixels of various physical features from SVI as indices for objectively-measured streetscape perceptions. On one hand, SVIs are different from conventional GIS datasets, they reflect a ground-level view of street (Seiferling et al., 2017). On the other hand, SVI data are easier to obtain, provide finer resolution with more details, and have wider data coverage (e.g., often publicly available at city scale) over traditional methods such as on-site auditing (Griew et al., 2013; Rundle et al., 2011). Additionally, crowdsourcing, computer vision (CV) and machine learning (ML) technologies have also proved their accuracy and efficiency for large-scale application (Naik et al., 2016, 2014). In particular, new studies within this regard have objectively detected curb ramps (Hara et al., 2014), measured eye-level greenery view index (GVI) (Li et al., 2015), counted pedestrian numbers (Yin et al., 2015), and predicted sun glare (Li et al., 2019).

Among this body of literature, several studies attempted to measure how objective measures of the eye-level perceptual qualities of streetscapes affect resident's daily lives and consequently their willingness to pay and housing prices. Yin \& Wang (2016) identified the proportion of sky as a significant measure of the visual enclosure for walkability. A study used computer vision to quantify the street-visible greenery as GVI and estimated GVI's positive economic benefits on residential property value in Beijing (Y. Zhang \& Dong, 2018). Ye et al. (2019) found GVI measured from Baidu SVI obtained the third-highest and positive regression coefficient in the housing price hedonic model in Shanghai (Ye et al., 2019). Fu et al. (2019) extracted the view indices for tree, sky and building from Baidu panoramas in Beijing and Shanghai, and found tree and sky view significantly increased house prices. Chen et al. (2020) revealed the non-linear relationship between house prices and GVI in Shanghai that higher GVI were associated with higher value properties.

Nevertheless, although these new studies were able to address the associations between the objective measures of streetscapes and housing prices, they only accounted for less than three individual physical features. While the impact of greenery and sky view have been increasingly 
addressed, how many other important streetscape feature affect housing prices have never been tested. Additionally, prior studies failed to incorporate subjectively measured perceptual qualities. Perception is a seemingly comprehensive and subjective process of attaining awareness of sensory information (Ewing \& Handy, 2009). Street environment comprises of various visual elements, and these features individually cannot represent human-scale perceptions. Therefore, subjectively measured perception is likely to variate and complement the effects of objective measures, such as the recombination of visual elements or the individual view indices. No research exists to quantify the relationship between the eye-level and subjective assessment of streetscape perceptions and property values within current trend of utilizing deep learning and SVI frameworks.

\subsection{Potentials in the Context of Big Data and Deep Learning}

The number of studies in objective street measure have increased since 2006 (Humpel et al., 2004) as objective measurement exhibits advantages in translating perception results directly into actionable design interventions. However, a comprehensive investigation of the divergence and coherence between subjective and objective measurement protocols is necessary. On the one hand, many other important physical features that will affect human-scale perceptions of the street environment and consequently the property value have not been addressed adequately. For instance, the portion of transparent facades on the ground floor (Ewing \& Handy, 2009), urban furniture (Salazar Miranda et al., 2021), pedestrians (Yin et al., 2015), and commercial signs (F. Zhang et al., 2018) had not been addressed in HPM studies. On the other hand, physical features individually do not represent people's overall perception of the street environment. Subjective perceptions may have complex or subtle relationships to physical features (Ewing et al., 2006; Ewing \& Handy, 2009).

Subjective measures such as perceived assessments could serve as a tangible and firsthand counter-part to objective measures, helping clarify or even corroborate the meaning of the objective measures, and possibly justifying the value of using both types of measurements. While the impacts of objectively measured street environment perception on housing prices have been explored in a few studies emerged in recent years (Fu et al., 2019; Ye et al., 2019; Y. Zhang \& Dong, 2018), very few have considered the impact of subjectively measured streetscape perception (i.e. eye-level perceived qualities) on housing price.

The lack of subjective environmental measures in HPM studies is largely limited by the lack of large scale urban perception data from conventional survey based methods. Most data on urban environments appearance and perceptual qualities relied on low-throughput surveys (Lynch, 1960; Nasar, 1990). From Urban Design literature, besides greenery, indicators such as block length, street width, and building height have been utilized to objectively measure the streets (Cervero \& Kockelman, 1997). Obviously, to quantify perceptual quality, it requires more comprehensive and human-centered protocol besides there gross metrics (Brownson et al., 2004; Ewing \& Clemente, 2013). Ewing et al. (2006) first objectively measured five subjective urban design qualities from the street environment, namely imageability, enclosure, human scale, transparency and complexity (see Table 1). They used ratings from an expert panel which required large amount of human labor- a single video clip could take an hour. Similar to other conventional methods such as visual collage, mail or phone surveys (Humpel et al., 2004), the results were not reliable, since individual differences would make the evaluation inconsistent and therefore impractical (Nasar, 1990). In general, conventional survey methods are expensive, low throughput, coarse in spatial resolution (F. Zhang et al., 2018), and often subject to small city segment. Hence their conclusions are limited to the particular sample conditions (Seiferling et al., 2017) which weaken their generalizability.

More recently, participants can evaluate images using experts or crowdsourcing with online data collections, which have largely increased the data availability for built environment perceptions 
(Qiu et al., 2019; Salesses et al., 2013). At the same time, crowdsourced studies are ideal sources of the training dataset required by $\mathrm{ML}$ and $\mathrm{CV}$ frameworks to build scene understanding algorithms (Naik et al., 2014). In turn, the trained scene understanding algorithm are useful to create fine-grained urban perception maps across geographical regions. For instance, with thousands of geo-tagged images, Salesses et al. (2013) measured the perception of safety, class and uniqueness. They also found a significant correlation between the measured perceptions of safety and the number of homicides. Naik et al. (2014) predicted the perceived safety of street scenes using training data from an online survey with a scene understanding algorithm. F. Zhang et al. (2018) used ML algorithms to predict six stree scene perception scores, namely safe, lively, beautiful, wealthy, depressing and boring from SVI in Beijing and Shanghai. They also identified the visual elements that may cause a place to be perceived as different perceptions. Zhou et al. (2019) constructed an Integrated Visual Walkability Index with four sub-indicators (e.g., psychological greenery, visual crowdedness, outdoor enclosure, and visual pavement) which comprised of physical feature indices extracted from Baidu Map SVI to measure the spatial inequity of visual walkability for Shenzhen City (Zhou et al., 2019). Additionally, a most recent new study formed five objectively measured indices (e.g., openness, greenness, enclosure, walkability, and imageability) of the eye-level perception of street views and contrasted them with the corresponding subjectively-rated scores to inform the effectiveness of urban renewal (Ma et al., 2021). While acknowledging above advancements with deep learning and SVI for either subjective (Naik et al., 2014a; Salesses et al., 2013), or seemingly subjective but actually objective (Ma et al., 2021; F. Zhang et al., 2018; Zhou et al., 2019) streetscape perception measures for urban design and walkability literature, this study aims to bridge the knowledge gap where no systematic investigation of the impacts of subjective and objective measures of streetscape perceptions on housing price has been conducted.

\section{Data and Methods}

\subsection{Research Framework \& Study Area}

\subsubsection{Conceptual Framework}

Specifically, this study investigates and compares the impact of both objective and subjective measured street scene perceptions on housing price in Shanghai using an automotive, high-throughput and open-data framework. The ultimate research question investigated is to what extent subjective and objective environmental measures are complement or conflicting each other is never clearly stated in housing price literature. The operationalized and comprehensive framework to subjectively and objectively rate street environment is inspired by new information technologies including crowdsourced survey, open-source street imagery data, computer vision and machine learning. Three prior studies particularly raised our attention, namely the operational definitions of five seemingly subjective qualities (Ewing \& Handy, 2009), five objectively measured street scores based on features extracted from SVI (Ma et al., 2021), and the street scene understanding framework based on SVI and deep learning (Naik et al., 2014a).

Based on reviewing the place making, urban design, and street scene perception literature aforementioned, six perceptual qualities (i.e., Greenness, Walkability, Safety, Imageability, Enclosure, and Complexity) were selected to comprehensively present the eye-level street view perceptions both subjectively and objectively in this study. First, agreements of their significances in affecting residents' behavior, as well as their qualitative definitions have converged in literature. Additionally, their operational definitions for objective measures have also been more or less achieved (Table 1) (Ewing \& Handy, 2009; Ma et al., 2021; Mehta, 2014; F. Zhang et al., 2018). 
We conceptualize our research design as follows. First, the presence of physical features such as sidewalk, tree canopy, building, people affect residents' perceived street design qualities such as Safety, Imageability and Enclosure. In turn, these physical features together with the perceived qualities influence residents' reactions and their overall behaviors including to walk, to stay, to live and consequently the housing prices (Fig. 1). Notably, there were disagreements on whether sense of walkability, safety, and comfort belong to the perceptual qualities (Mehta, 2014) or actually counting for individual reactions (Ewing \& Handy, 2009). Since our focus is the impact of perceptual qualities on house prices, we follow Mehta (2014) and F.Zhang et al. (2018) and treat the sense of Safety and Walkability as perceptual qualities (just like imageability, enclosure and complexity) rather than individual actions by Ewing \& Handy (2009).

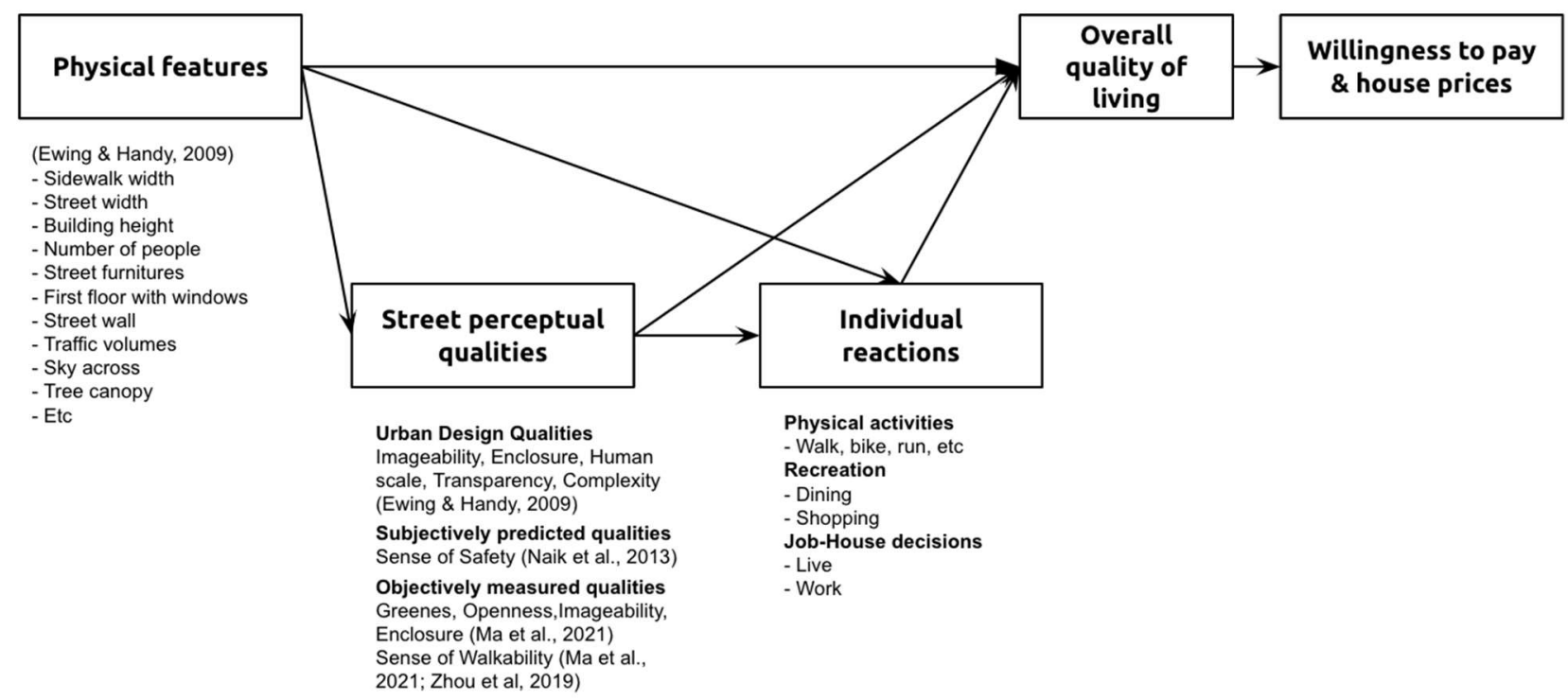

Figure 1. Conceptual framework. Inspired by Ewing \& Handy (2009)

\subsubsection{Analytical Framework}

First, we collected perceptual ratings of six perceptual streetscape qualities on $\mathbf{3 0 0}$ randomly sampled SVI across Shanghai area. The subjective perception qualities were collected from 30 participants with an online survey where a participant can choose her preferred street scene from pairwise SVIs regarding a perceptual quality question such as "Which place looks greener?". Such an online survey method have been proved to efficiently and accurately reveal people's true preferences (Salesses et al., 2013). Because the definition of six perceptions are not self-evident to the average person, it was not feasible to ask a random sample of residents to rate street environments with regard to qualities such as 'imageability' (Ewing \& Handy, 2009). Therefore, all participants are graduate students in Architecture, City Planning and Landscape Architecture majors who attended a design workshop (DigitalFUTURES, 2020). They comprised of an expert panel similar to Ewing \& Handy (2009). The spatial location of SVIs was not revealed to participants and the pairwise comparison did not allow a draw. Second, the pairwise preferences were translated to ranked perception scores using Microsoft TrueSkill (Minka et al., 2018; Naik et al., 2014a) rating algorithm for each image. Third, we extracted and quantified the percentile indices of about thirty important physical features and then trained ML models to predict the perceived scores using the physical feature indices extracted from the images as independent variables. The perception score prediction algorithms achieved high accuracy rates. Fourth, we predicted the eight subjective perceptual scores for all SVI sampled across Shanghai metropolitan area (in total 25,276 images) based on their semantic feature pixel indices. Last, we added both the subjective rating scores and objectively measured street feature indices to a 
hedonic price model with other important structural, locational and neighborhood attributes using housing transaction data in Shanghai collected from HomeLink (Lianjia.com, the largest real estate website in China).

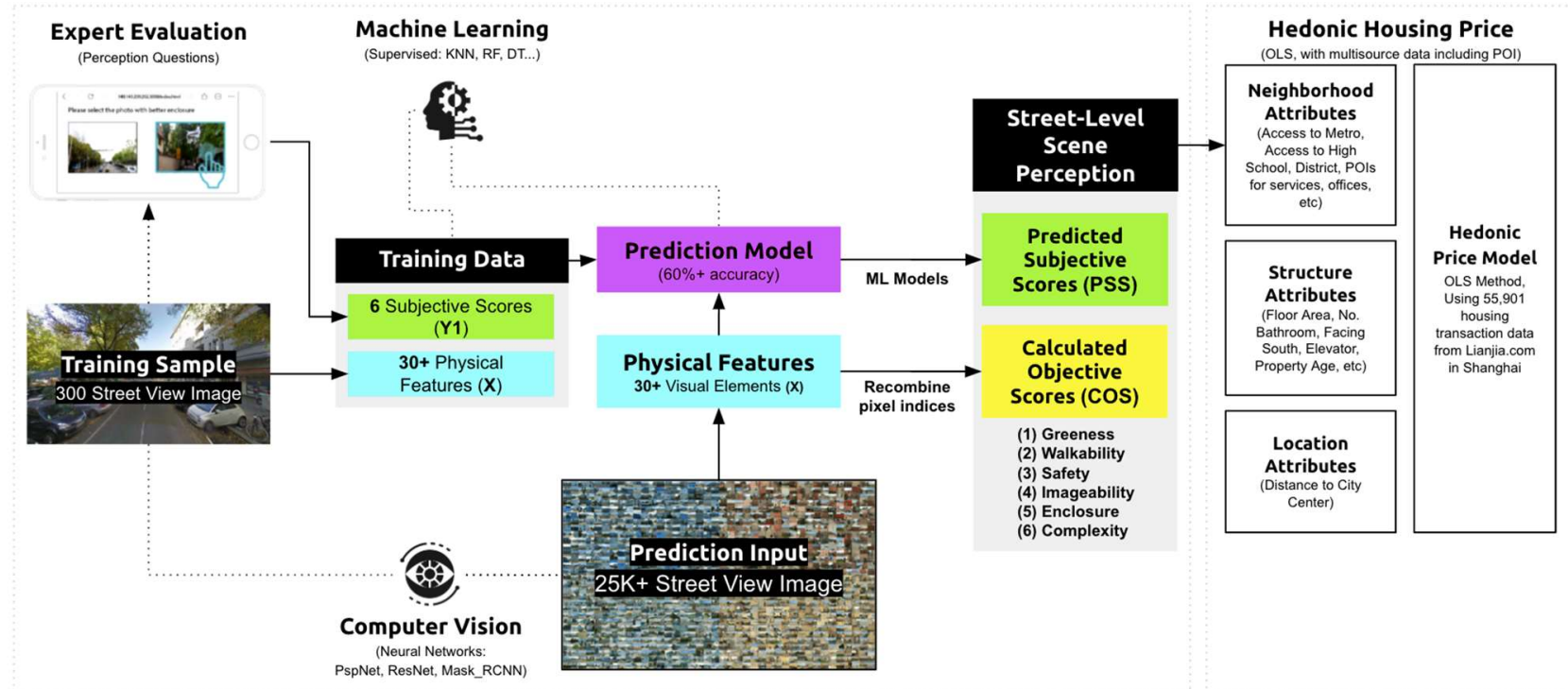

Figure 2. Analytical framework

With HPM approach, we quantified the effects between the human-centered subjective and objective measures of streetscape perceptions and the neighboring housing prices. We systemically compared the achieved standardized coefficients for subjective measures and objectives, as well as with other involved structure, location, and neighborhood attributes. This helped to answer three questions: (1) To what extent would subjectively-measured eye-level streetscape perception affect housing price? (2) Would the subjective measured indicators play a more important role than that of objective measures? (3) What are the divergence and coherence between the two kinds of measures?

\subsubsection{Study Area}

The municipality region of Shanghai was selected as the study area. Shanghai is the financial, center of China, with a population density of 17,000 people $/ \mathrm{km}^{2}$. Since the housing reform in 1998 , Shanghai has become one of the most expensive and vibrant housing markets in China (Chen et al., 2020). An empirical analysis for the city-wide area of Shanghai would provide essential implications for relevant studies.

\subsection{Selection of the Six Perceptual Qualities}

Better perceived street environment qualities provide many health, environmental, and social benefits, so they may be considered important factors in residents' choice of living, therefore will affect housing prices. Second, many empirical studies showed that the level of walkability (E. J. Kim \& Kim, 2020; Leinberger \& Alfonzo, 2012), greenery (Ye et al., 2019; Y. Zhang \& Dong, 2018), openness (Chen et al., 2020; Fu et al., 2019), safety (Ceccato \& Wilhelmsson, 2020; Naik et al., 2014), aesthetics (Cetintahra \& Cubukcu, 2015; Jim \& Chen, 2009; Quercia et al., 2014), and risks (McCluskey \& Rausser, 2001) in a neighborhood all have correlations with residents' everyday behaviors, psychological perceptions of the place, wiliness to pay, and eventually the surrounding property values. 
Motivated by two measurement protocols of street environment for walkability (Ewing \& Handy, 2009) and urban renewal (Ma et al., 2021), we selected six successfully operationalized perceptions, namely (1) Greenness, (2) Walkability, (3) Safety, (4) Imageability, (5) Enclosure, and (6) Complexity to present the eye-level streetscape qualities. Their definitions and associated physical features are depicted in Table 1.

In particular, the selection of these qualities are based on a comprehensive review on the scene perception literature aforementioned. There has been agreements but also divergence in the qualitative definitions and operational measurements. On the one hand, Ewing \& Handy (2009) successfully defined and measured five important qualities (e.g. Imageability, Enclosure, Transparency, Human Scale, and Complexity) by statistically establishing the relationships between physical features and subjective ratings from expert panels. Their qualitative definitions are kept in this study. Second, Ma et al. (2021) constructed objective measures of five qualities (e.g. Greenness, Openness, Walkability, Enclosure and Imageability) by recombining certain physical features' pixel indices extracted from SVI into equations. Among them, Greenness (Chen et al., 2020; Fu et al., 2019; Ye et al., 2019; Y. Zhang \& Dong, 2018) and Walkability (E. J. Kim \& Kim, 2020) have been implied to significantly affect property value in literature. We deleted Openness but keep Enclosure to avoid multicollinearity problems: by definition they both emphasize vertical elements in street view; and by operation sky view and building view are among the most significant elements for both of them. Therefore, four qualities were kept in this study as objective measures. Additionally, perceived safety (from crime specifically) has been consistently assigned great importance to the quality of street and public space: it significantly affects resident's behaviors that eventually associated to housing prices (Buonanno et al., 2013; He et al., 2017; Mehta, 2014; Naik et al., 2014a; F. Zhang et al., 2018). Prior studies implied that in districts perceived as being less safe from surveys (Buonanno et al., 2013) or with higher crime rates (Ceccato \& Wilhelmsson, 2020), houses are highly discounted. However, how perceived safety from street appearance will affect house prices has not been clearly stated in literature. Therefore, we also adds Safety to complement the other five well-established and operationalized qualities.

Both subjectively perceived ranking scores and objectively measured quality scores are operationalized with a large SVI dataset in Shanghai metropolitan area with respect to the eight streetscape qualities. On the one hand, subjectively perceived scores are predicted from SVI with machine learning models taking the results of an online survey as training data. The method is inspired by scene understanding frameworks established by prior studies based on the integration of crowdsourcing survey, computer vision and machine learning (Naik et al., 2016, 2014a; F. Zhang et al., 2018). On the other hand, the objective scores are calculated by combining the indices of significant physical features extracted from SVI. Notably, significant visual elements for each quality are also identified by aforementioned literature (Ewing et al., 2006; Ewing \& Handy, 2009; Ma et al., 2021; Zhou et al., 2019). The definitions and equations to construct the scores are depicted in Table 1 . 
Table 1. Summary of definitions and equations for six perceptual qualities

\begin{tabular}{|c|c|c|c|c|}
\hline $\begin{array}{l}\text { Perceptual } \\
\text { Quality }\end{array}$ & Qualitative Definition & Significant physical features & $\begin{array}{l}\text { Subjective Score } \\
\text { Questions }\end{array}$ & $\begin{array}{l}\text { Objective Score Equations } \\
\text { (based on their operational definitions) }\end{array}$ \\
\hline $\begin{array}{l}1 . \\
\text { Greenness }\end{array}$ & $\begin{array}{l}\text { Urban Greenpace that are an } \\
\text { essential element in streetscape, } \\
\text { including forests, greenbelts, and } \\
\text { lawns. (Ma et al., 2021) }\end{array}$ & $\begin{array}{l}\text { Tree view (Li et al., 2015; Ma et } \\
\text { al., 2021; Seiferling et al., 2017) }\end{array}$ & $\begin{array}{l}\text { Which place looks } \\
\text { Greener? }\end{array}$ & $\begin{array}{l}\text { The proportion of Greenpace vegetation intermixed } \\
\text { with building façades. (Ma et al., 2021) } \\
\qquad \text { O1_Greens } s_{i}=V I_{\text {tree }}(2.1)\end{array}$ \\
\hline $\begin{array}{l}2 . \\
\text { Walkability }\end{array}$ & $\begin{array}{l}\text { The psychological impact of the } \\
\text { surrounding visual elements on the } \\
\text { walking experience, such as the } \\
\text { sense of comfort and pleasure for } \\
\text { walking. (Ma et al., 2021) }\end{array}$ & $\begin{array}{l}\text { Pavement, sidewalk, fence, tree, } \\
\text { grass (Ma et al., 2021; Zhou et } \\
\text { al., 2019) }\end{array}$ & $\begin{array}{l}\text { Which place looks } \\
\text { more Walkable? }\end{array}$ & $\begin{array}{l}\text { The proportional relationship between the } \\
\text { pavement, fence and the overall road on the walking } \\
\text { experience. (Ma et al., 2021) } \\
\qquad \text { O2_Walkb }{ }_{i}=\frac{V I_{\text {sidewlk }}+V I_{\text {fence }}}{V I_{\text {road }}}(2.2)\end{array}$ \\
\hline $\begin{array}{l}3 . \\
\text { Safety }\end{array}$ & $\begin{array}{l}\text { An individual's experience of the } \\
\text { risk of becoming a victim of crime } \\
\text { and disturbance of public order. } \\
\text { (Jansson, 2019) }\end{array}$ & $\begin{array}{l}\text { Visual and physical connection } \\
\text { and openness to adjacent } \\
\text { spaces, physical condition and } \\
\text { maintenance, lighting quality in } \\
\text { space after dark, presence of } \\
\text { surveillance cameras, security } \\
\text { guards, guides, ushers, etc. }\end{array}$ & $\begin{array}{l}\text { Which place looks } \\
\text { safer? }\end{array}$ & $\begin{array}{l}\text { Perceived safety from crime is affected by the } \\
\text { physical condition and maintenance, the } \\
\text { configuration of spaces, the types of land uses, the } \\
\text { alterations and modifications made to the } \\
\text { environment, and the presence or absence of, and } \\
\text { the type of, people. (Mehta, 2014) } \\
\text { O3_Safty }{ }_{i}=V I_{\text {persn }}+V I_{\text {signb }}+V I_{\text {strlgt }}+ \\
\qquad V I_{\text {fence }}+V I_{\text {windwp }}(2.3)\end{array}$ \\
\hline $\begin{array}{l}4 . \\
\text { Imageability }\end{array}$ & $\begin{array}{l}\text { The quality of a place that makes it } \\
\text { distinct, recognizable and } \\
\text { memorable. (Ewing \& Handy, 2009) }\end{array}$ & $\begin{array}{l}\text { People, proportion of historic } \\
\text { buildings, courtyards / plazas/ } \\
\text { parks, outdoor dining, buildings } \\
\text { with non-rectangular } \\
\text { silhouettes, noise level, major } \\
\text { landscape features, buildings } \\
\text { with identifiers (Ewing \& } \\
\text { Handy, 2009) }\end{array}$ & $\begin{array}{l}\text { Which place has } \\
\text { better Imageability? }\end{array}$ & $\begin{array}{l}\text { The proportions of the buildings, signs and symbols } \\
\text { as a proxy of street richness and diversity. (Ma et } \\
\text { al., 2021) } \\
\quad 04{ }_{-} I g b l_{i}=V I_{\text {bldg }}+V I_{\text {skycrp }}+V I_{\text {signb }} \text { (2.4) }\end{array}$ \\
\hline $\begin{array}{l}5 . \\
\text { Enclosure }\end{array}$ & $\begin{array}{l}\text { The degree to which streets and } \\
\text { other public spaces are visually } \\
\text { defined by buildings, walls, trees } \\
\text { and other vertical elements. (Ewing } \\
\& \text { Handy, 2009) }\end{array}$ & $\begin{array}{l}\text { Proportion street wall, } \\
\text { proportion sky across, long } \\
\text { sight lines, proportion sky ahead } \\
\text { (Ewing \& Handy, 2009) }\end{array}$ & $\begin{array}{l}\text { Which place has } \\
\text { better Enclosure? }\end{array}$ & $\begin{array}{l}\text { The degree to which street canyons are visually } \\
\text { enclosed by the sides of buildings, walls, trees and } \\
\text { other vertical elements and the space of the } \\
\text { horizontal ground between them. (Ma et al., 2021) } \\
\qquad \text { O5_Encls }{ }_{i}=\frac{V I_{\text {bldg }}+V I_{\text {tree }}}{V I_{\text {road }}+V I_{\text {sidewlk }}+V I_{\text {earth }} \text { VIgrass }_{\text {gras }}}\end{array}$ \\
\hline $\begin{array}{l}6 . \\
\text { Complexity }\end{array}$ & $\begin{array}{l}\text { The visual richness of a place, } \\
\text { which depends on the variety of the } \\
\text { numbers and types of buildings, } \\
\text { ornamentation, landscape elements, } \\
\text { street furniture, signage and human } \\
\text { activity. (Ewing \& Handy, 2009b) }\end{array}$ & $\begin{array}{l}\text { People, buildings, dominant } \\
\text { building colors, accent colors, } \\
\text { outdoor dining, public art } \\
\text { (Ewing \& Handy, 2009) }\end{array}$ & $\begin{array}{l}\text { Which place has } \\
\text { better Complexity? }\end{array}$ & $\begin{array}{l}\text { The numbers and kinds of buildings, } \\
\text { architectural diversity and ornamentation, landscape } \\
\text { elements, street furniture, signage, and human } \\
\text { activity. (Ewing et al., 2006) } \\
O 6_{\text {C_Cmplx }}= \\
\frac{V I_{\text {persn }}+V I_{\text {signb }}+V I_{\text {strlgh }}+V I_{\text {tree }}+V I_{\text {chair }}+V I_{\text {windwp }}}{V I_{\text {bld }}+V I_{\text {road }}}\end{array}$ \\
\hline
\end{tabular}

Notes: (1) $\boldsymbol{V} \boldsymbol{I}_{\text {feature }}$ denotes the view index of a physical feature (proportion of the visual element's pixels in a SVI), and is calculated as:

$V I_{\text {feature }}=\frac{\sum_{i=1}^{n} \text { Pixel }_{\text {feature }}}{\sum_{i=1}^{m} \text { Pixel }_{\text {total }}}=\frac{1}{n} \sum_{i=1}^{n}$ Pixel $_{\text {feature }}$, feature $\in\{$ tree, building, sky, etc $\}[1]$.

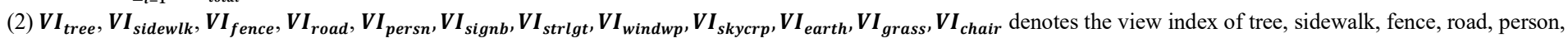
signboard, streetlight, windowpane, skyscraper, earth, grass, and chair respectively

\subsection{Calculating Subjective and Objective Perceptual Scores}

SVI provides a horizontal perspective of the street environment which is closer to a pedestrian's eye-level perception (Li et al., 2015; Seiferling et al., 2017), therefore it becomes an ideal data source for the measures of human-centered streetscapes (Fig. 3a). Several prior studies have established efficient frameworks to predict subjective or objective perceptual scores from SVIs. One the one hand, 
Naik et al (2014) demonstrated that the combination of generic image features and the scores of perceived safety from a crowdsourced study can accurately predict the safety scores of streetscapes not used in the training dataset. Their method lays the foundation for the subjective score prediction in this study. On the other hand, many studies (Ewing \& Handy, 2009; Ma et al., 2021; Zhou et al., 2019) objectively measure seeming subjective urban design qualities such as enclosure, complexity, greenness, and walkability based on establishing the statistic relationships between important physical elements and the quality ratings; they provide operationalized framework for the objectively measured scores in this study.

In particular, the process of calculating subjective and objective perceptual qualities from SVI comprised of five steps: (1) downloaded SVIs from sampled sites; (2) collected and converted people's preference to ranked quality perception scores as training labels; (3) extracted pixel percentile indices of different visual elements from SVIs as independent variables in the training dataset; (4) trained ML models to predict subjective scores based on the independent variables; and (5) calculated objective scores based on formulas (see Table 1) that recombining view indices of selected visual elements.

\subsubsection{Collection of SVIs}

SVI data were sampled at 50-meter intervals (Ma et al., 2021) along the centerline of public streets within 1-km radius of property's coordinates. The typical block size in Shanghai is 6.8 hectares (NYU et al., 2016), with block width and length range between 300-500 meters. Therefore, a 50-m interval will ensure 6-10 images sampled for each block edge. 1-km radius was determined because Chinese cities advocate a 15-minute walking distance for delineating a neighborhood which is about $1 \mathrm{~km}$ (Zhou et al., 2019). The sampling was processed in ArcGIS.

Each sample's SVI was downloaded by feeding coordinates into Baidu Street View API (BAIDU, 2020; Dopico, 2020) which is the most used web map service in China. To ensure consistent view angle, we kept same camera settings and image resolution (Fig. 3b). In addition, for each SVI we also selected similar shooting time (summer and fall 2017) identified by filename to eliminate the seasonal variance in street environments. In total we downloaded 25,276 valid SVIs.

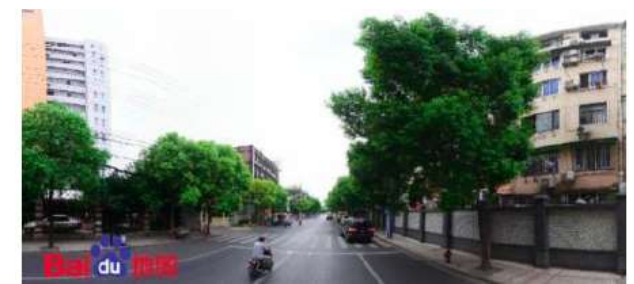

(a) A random SVI sample

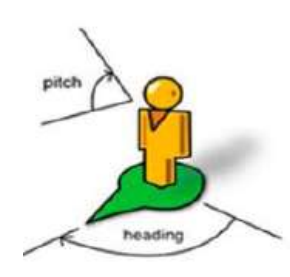

(b) Configurations

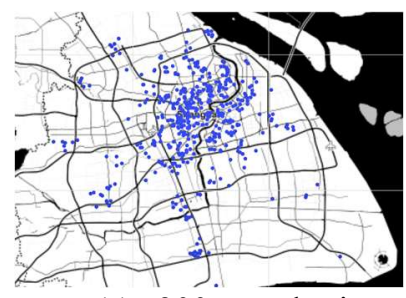

(c) 300 sample sites

Figure 3. Downloading Baidu SVIs (a) A random SVI sample. (b) Viewpoint of all SVIs were consistent by controlling three parameters: the "heading" (view direction) was set paralleled to the street centerline, the "FOV" (horizontal field of view) was 120 degree, and the "pitch" (the up or down angle of the camera) was 0 degree. In addition, the resolution was $640 \times 360$ pixels. (c) Training images were sampled across a wide range of geographical locations in Shanghai.

\subsubsection{Collecting Subjective Perception Scores from Online Survey}

To collect subjective streetscape perceptions as training labels, we adopted a high-throughput urban scene understanding framework (Naik et al., 2014; Salesses et al., 2013) which integrated crowdsourced survey data, deep learning and ML. We built a survey website where participants were 
shown two pairwise SVIs and were asked to click on the preferred image in response to six perceptual evaluation questions (Fig.4a). Take Imageability as example, we first gave a qualitative definition on this quality. Participants were then asked "Which place has higher degree of Imageability". To ensure the SVIs shown in the survey capture a variety of streetscapes from city center, suburban to countryside, we randomly sampled 300 SVIs across Shanghai (Fig. 1c). In total 45 graduate-level students major in built environment and design disciplines participated. 300 sample SVIs were ranked with 4426 pairwise clicks. These preferences were later converted to ranked scores with TrueSkill algorithm which is a Bayesian skill rating system (Microsoft, 2005; Minka et al., 2018). On average, every SVI in the survey was compared to other 15 SVIs, which was sufficient for TrueSkill to converge to stable ranking scores (Naik et al., 2014). Scores were then normalized to 0-10 scale where 1 the best and 10 the worst. These 300 SVIs labelled with six subjective scores became the training labels that we later trained ML algorithms to predict subjective scores for all other unranked SVIs.
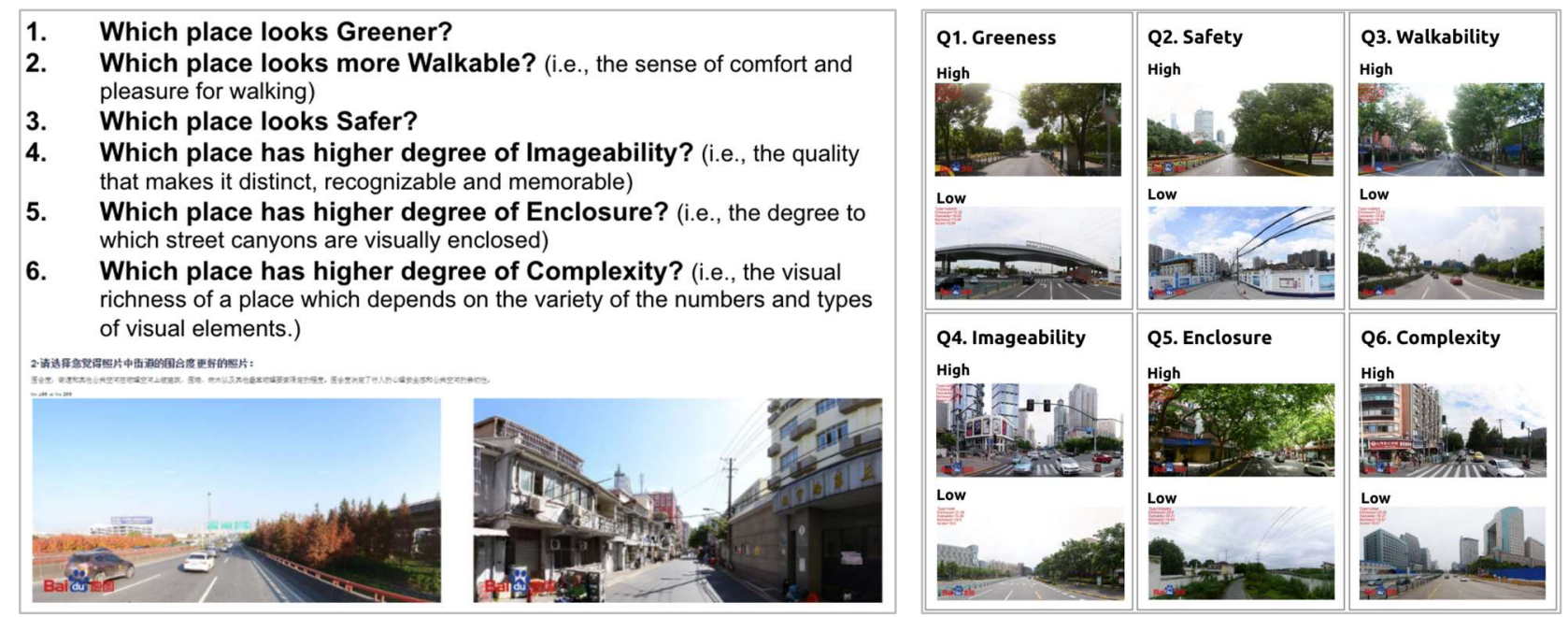

Figure 4. Collecting subjective streetscape perceptions with an online survey platform (a) The website allowed participants to click on one of pairwise images in response to the six evaluative questions. (b) High- and low-score examples for the six subjective perception qualities. Regarding Greenness, participants preferred more greeneries including tree, plants, and grass; for Imageability, participants seemed to prefer streetscapes with iconic buildings and landmarks; for Walkability \& Enclosure, street views with less sky exposure, more sidewalks, more tree canopy and plants are preferred; for Complexity and Safety, scenes with commercial activities on the ground floor are chosen.

\subsubsection{Classification of the physical features}

Prior studies have statistically identified physical features from streetscape that lead to different perception qualities (Ewing \& Handy, 2009; Ma et al., 2021; F. Zhang et al., 2018; Zhou et al., 2019). Particularly, view index of individual visual element was often utilized as an important indicator, which was defined as the percentage of the feature's pixels to the total pixels in a SVI (Fu et al., 2019). For instance, sky view index represents the percentage of sky pixels in a SVI. View index captures the importance of a visual element in a pedestrian's eye-level view. Therefore, the appearance of various physical features in SVIs were measured by the general formula (1) as follows.

$$
V I_{\text {feature }}=\frac{\sum_{i=1}^{n} \text { Pixel }_{\text {feature }}}{\sum_{i=1}^{m} \text { Pixel }_{\text {total }}}=\frac{1}{n} \sum_{i=1}^{n} \text { Pixel }_{\text {feature }}, \text { feature } \in\{\text { tree, } \text {, building, sky, etc }\}
$$

where $V I_{\text {feature }}$ the view index of a physical feature, $\sum_{i=1}^{n} P I X E L_{\text {total }}$ the total number of pixels, and $\sum_{i=1}^{n} P I X E L_{o b j}$ the number of pixels associated with the physical feature in a SVI. 
Pyramid Scene Parsing Network (PSPNet) which involves a pixel-level object recognition and classification (Zhao et al., 2016) was adopted to extract and calculate the view index of each feature from SVIs. PSPNet framework have made remarkable achievements in semantic segmentation- it reached more than $93.4 \%$ pixel-level accuracy, and has been applied by several studies to extract features for housing price studies (Fu et al., 2019). Fig.5 showed eight randomly sampled SVIs with their segmentation results.
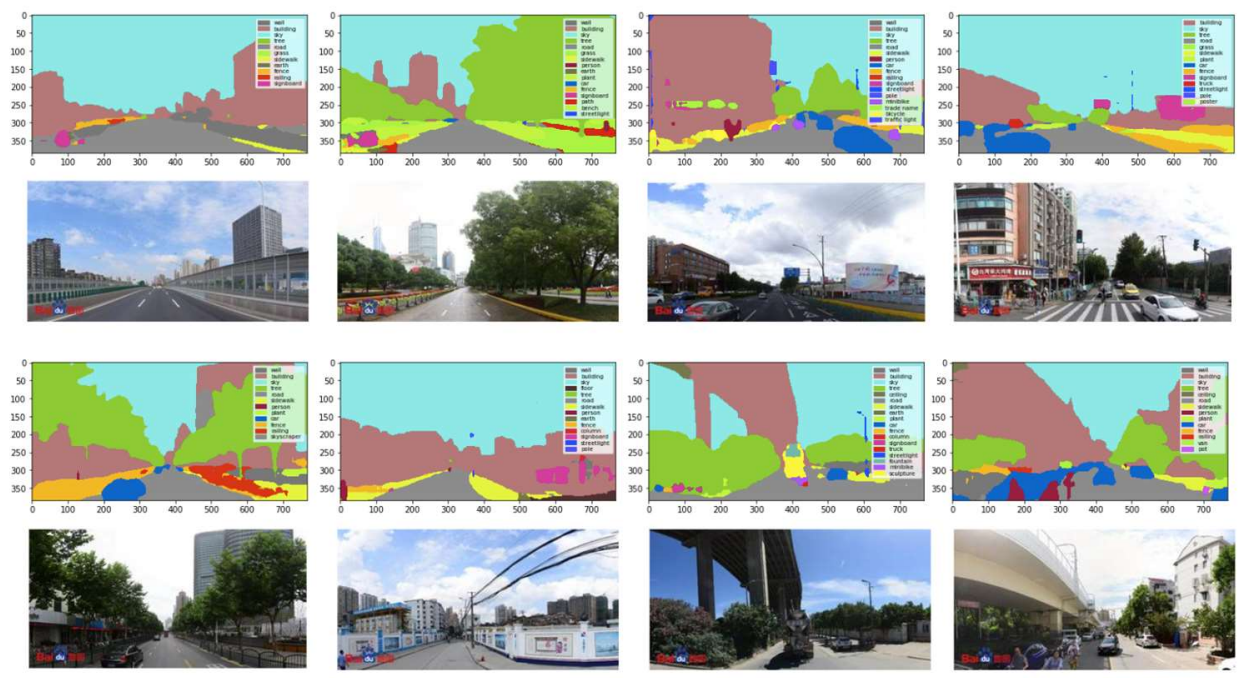

Figure 5. CV Segmentation Results. Pairwise photos illustrate the raw input SVI and its semantic segmentation result.

\subsubsection{Prediction of Subjective Perception Scores}

With the 300 training images whose ranked scores from online survey as labels and the extracted view indices as explanatory variables, we trained and compared various ML models to predict the six subjective scores. The 300 samples were split to $80 \%$ and $20 \%$ for training and testing purposes. Eight widely-applied ML models including Random Forest (RF), Support Vector Machine (SVM), Gradient Boost (GB), and Decision Tree (DT) were tested. To choose the optimal model, we compared model performances in terms of the R-square $\left(\mathrm{R}^{2}\right)$ and the Mean Absolute Error (MAE).

\subsubsection{Calculation of Objective Perception Scores}

Lastly, based on the equations recombining significant visual elements' view indices in Table 1, we took the percentile indices of relevant physical features of each image to calculate the objective scores for 300 training images and also all the SVIs sampled across Shanghai as the objectively measured scores. After calculation, these scores were normalized to $0-1$ scale $(0$ the worst and 1 the best) for interpretation purpose.

\subsubsection{Verification of Scores}

For the 300 training images, their objective scores were also compared with subjective scores to investigate the coherence and divergence between the visually-experienced perceptual qualities and the formula-derived ones. Additionally, for both subjective and objective scores, Pearson correlation 
analysis was also applied to validate the multicollinearity of the six qualities respectively to investigate the multicollinearity.

\subsection{Hedonic Housing Price Model}

HPM method assumes housing is a heterogeneous good whose price determinants can be investigated by regressing the house price on three main groups of explanatory variables capturing the property's structure, location and neighborhood attributes (Rosen, 1974). It has been widely applied to quantify to what extent built environment factors affect property values (Chen et al., 2020; Larsen \& Blair, 2014; Y. Zhang \& Dong, 2018). Specifically, structure attributes include variables that describe the characteristics of the house such as building age, floor area, number of bathrooms, house orientation and elevator. Location characteristics often include the distance to the city center. Neighborhood attributes capture the accessibility of important urban facilities (such as trees, parks, plazas, metro stations, and healthcare, finance and education services). Although the streetscape scores could be put into neighborhood attributes, we still categorized them into a new attribute group (STRE) to address the effects of human perceptions. Therefore, the conventional HPM is extended as follows in our study:

$$
\text { PRICE }=\alpha+\beta_{1} \text { STRU }+\beta_{2} \text { LOCA }+\beta_{3} \text { NEIG }+\beta_{4} \text { STRE }+\varepsilon,[2]
$$

where PRICE the housing price, $\alpha$ is the constant, $\beta_{1}$ to $\beta_{4}$ the coefficients estimated for structure (STRU), location (LOC), neighborhood (NEIG), and streetscape (STRE) attributes respectively, and $\varepsilon$ the error term.

\subsubsection{Housing Transactional Price}

Transaction records of apartments occurring in 2019 within Shanghai were collected from Lianjia.com, a Chinese real estate brokerage company (Wikipedia, 2020) which provide pre-owned apartment's information. The transaction records also included information of the property's structure attributes and coordinates. In total 65,000 records were downloaded and the dataset was cleaned for (1) records whose transaction price seemed not reliable (e.g. zero value, or per unit price was more than ten times greater or smaller than the average); and (2) records whose property attributes were missing. In the end, 40,159 geo-tagged records were kept, with an average price at 57,349 RMB $/ \mathrm{m}^{2}$. Fig.6a depicted the price distribution. For the regression model, transaction price were then transformed to natural logarithm form as the dependent variable (Chen et al., 2020; Rosen, 1974).

\subsubsection{Independent Variables}

Four types of independent variables were selected (Table 2) based on literature and data availability. Structure attributes included continuous variables such as the unit's total floor area, number of bathrooms, building age, and categorical variables such as floor level, building height, the layout type, building structure type, unit orientation (whether has south-facing rooms), degree of interior decoration, and the availability of elevator. Categorical variables were transformed to dummies.

Regarding location attributes, many studies identified that when distances to the city center increased, housing prices decreased (Bourassa et al., 2010; Chen et al., 2020; Rosen, 1974). We then calculated the road network distance from each property (1) to the Bund - CBD of Shanghai and (2) to their nearest county center as locational attributes. We also included dummy variables indicating the property's district or ring-road location to capture sub-market effects (Bourassa et al., 2010). The 
distance calculation was completed based on 2018 Shanghai road network data from Open Street Map (OSM) in QGIS.

Neighborhood attributes measured either the density, distance to, or the accessibility to different urban amenities and services. The density of service calculated the number of amenities such as retailing, restaurants, cafes, groceries, hospitals and gyms per $\mathrm{km}^{2}$ within the neighborhood's administration (district) boundary. Particularly, school district setting and education quality play an important role on housing price (Wen et al., 2017): a good school district provides a high price premium. Therefore, we took 68 high schools of excellent education quality (recognized by Shanghai government) into account. Distance variables were calculated the road network distance to the closest metro station or to the closest high schools to incorporate the significant impacts of public transit and education. Accessibility to metro stations or high schools) was also measured by taking the numbers of metro stations or high schools) reachable within $1 \mathrm{KM}$ or $5 \mathrm{KM}$ respectively. Neighborhood's boundary came from 2018 Shanghai GIS Shapefile. Data for living services and amenity were collected from Dazhongdianping.com while locations of metro stations and schools were from AutoNavi's map service (also known as Gaode) respectively (Fig. 6b).

In terms of streetscape perception attributes, we took the six ML-predicted subjective scores or the formula-derived objective counterparts into HPM separately.
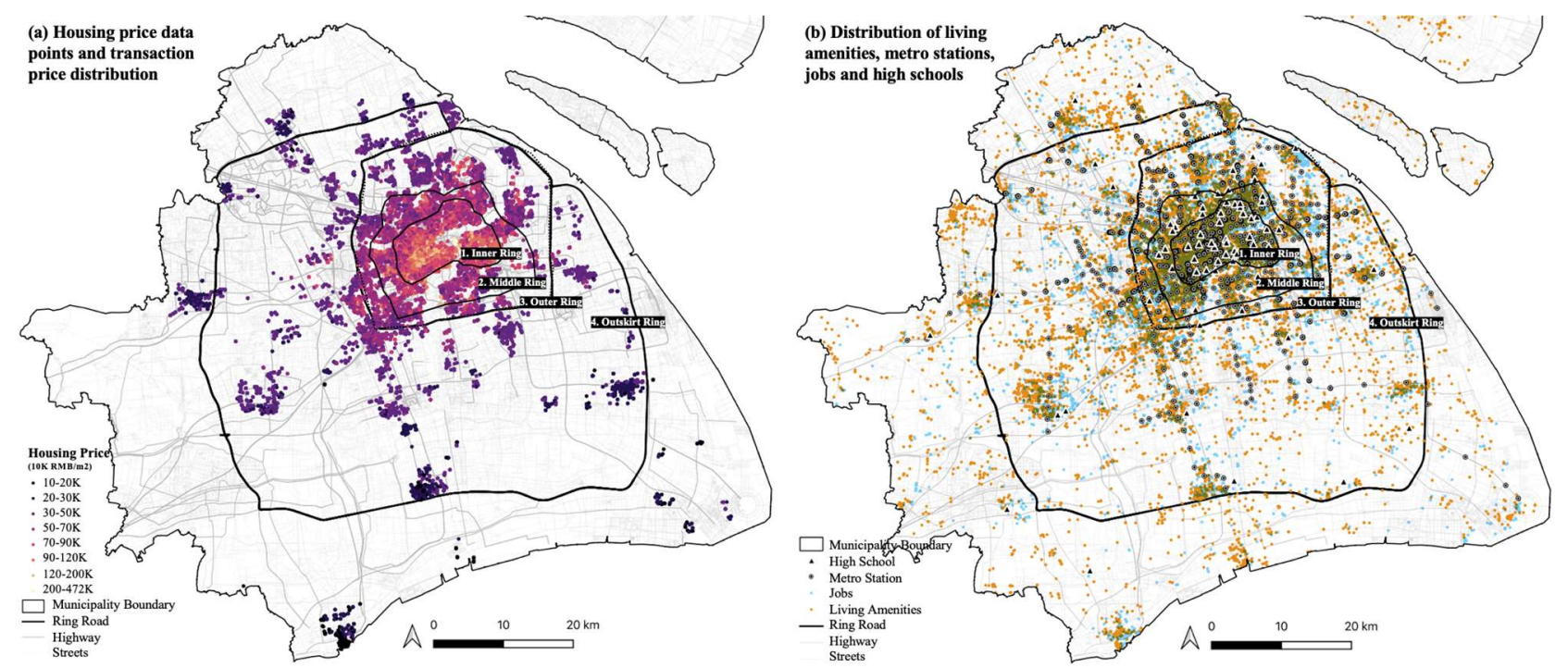

Figure 6. Spatial distribution of (a) 2019 transaction housing price data from HomeLink, and (b) neighborhood attributes including living amenities, metro station, job opportunities, and high schools

Table 2. General descriptive statistics of the housing characteristic

\begin{tabular}{|c|c|c|c|c|c|c|c|c|}
\hline Variables & Description & & Count & Mean & Std. Dev. & Min & Max & Data Source \\
\hline PRICE & Transactional price $(\mathrm{RMB} / \mathrm{m} 2)$ & & 40159 & 57349 & 21683 & 10400 & 250813 & Lianjia.com \\
\hline \multicolumn{9}{|c|}{ STRUCTURAL ATTRIBUTES } \\
\hline FLAREA & Total floor area of the unit (m2) & & 40159 & 85 & 43 & 15 & 588 & \multirow{7}{*}{$\begin{array}{l}\text { Web scraping from } \\
\text { Lianjia.com }\end{array}$} \\
\hline BEDRM & Number of bedrooms & & 40159 & 2.1 & 0.8 & 1 & 8 & \\
\hline LIVRM & Number of living rooms & & 40159 & 1.4 & 0.6 & 0 & 5 & \\
\hline КITCH & Number of kitchens & & 40159 & 1.0 & 0.2 & 0 & 5 & \\
\hline BATH & Number of bathrooms & & 40159 & 1.2 & 0.5 & 0 & 7 & \\
\hline TTLFLR & Total floors of the building & & 40159 & 11.0 & 7.9 & 1 & 62 & \\
\hline \multirow[t]{2}{*}{ CSTRYR } & Construction year of the building & & 40159 & 1998 & 9.4 & 1912 & 2019 & \\
\hline & & Values & Count & $\%$ & $\begin{array}{l}\text { Ave. Price } \\
(¥ / \mathrm{m} 2)\end{array}$ & $\begin{array}{l}\text { Ave. Area } \\
\text { (m2) }\end{array}$ & & Data Source \\
\hline HGHT & & Base & 1 & $0.0 \%$ & 34,452 & 87 & & \\
\hline
\end{tabular}




\begin{tabular}{|c|c|c|c|c|c|c|c|c|}
\hline & Categorial variables, & High & 17084 & $42.5 \%$ & 55,092 & 79 & & \multirow{20}{*}{$\begin{array}{l}\text { Web scraping from } \\
\text { Lianjia.com, converted to } \\
\text { dummy variables with } \\
\text { Python to dummies library }\end{array}$} \\
\hline & on which floor in the building is the & Low & 11231 & $28.0 \%$ & 59,160 & 93 & & \\
\hline & unit located? & Mid & 11843 & $29.5 \%$ & 58,891 & 86 & & \\
\hline \multirow{3}{*}{ LAYT } & Categorial variables, & Duplex & 1632 & $4.1 \%$ & 58,108 & 154 & & \\
\hline & the layout of the unit & Flat & 38527 & $95.9 \%$ & 57,317 & 82 & & \\
\hline & & Bungalow & 5 & $0.0 \%$ & 76,376 & 114 & & \\
\hline \multirow{3}{*}{ BTYPE } & Categorial variables, & Mix & 207 & $0.5 \%$ & 72,013 & 106 & & \\
\hline & the size and shape of the building & Slab & 36379 & $90.6 \%$ & 56,346 & 85 & & \\
\hline & & Tower & 3568 & $8.9 \%$ & 66,706 & 88 & & \\
\hline \multirow{2}{*}{ STH_NTH } & Categorial variables, & Else & 7993 & $19.9 \%$ & 56,110 & 94 & & \\
\hline & is the unit south facing? & South & 32166 & $80.1 \%$ & 57,657 & 83 & & \\
\hline \multirow{3}{*}{ STRC } & \multirow{3}{*}{$\begin{array}{l}\text { Categorial variables, } \\
\text { the structure of the building }\end{array}$} & Brick & 17944 & $44.7 \%$ & 53,060 & 61 & & \\
\hline & & Other & 59 & $0.2 \%$ & 58,984 & 81 & & \\
\hline & & Steel & 22156 & $55.2 \%$ & 60,819 & 105 & & \\
\hline \multirow{4}{*}{ DÉCOR } & \multirow{4}{*}{$\begin{array}{l}\text { Categorical variable, } \\
\text { the interior quality of the unit }\end{array}$} & Blank & 1903 & $4.7 \%$ & 47,779 & 84 & & \\
\hline & & Other & 2863 & $7.1 \%$ & 53,395 & 79 & & \\
\hline & & Refined & 20859 & $51.9 \%$ & 61,322 & 96 & & \\
\hline & & Simple & 14534 & $36.2 \%$ & 53,680 & 72 & & \\
\hline \multirow{2}{*}{ ELEVTR } & \multirow{2}{*}{$\begin{array}{l}\text { Categorical variable, } \\
\text { is elevator available? }\end{array}$} & No & 24106 & $60.0 \%$ & 52,764 & 69 & & \\
\hline & & Yes & 16053 & $40.0 \%$ & 64,235 & 110 & & \\
\hline \multicolumn{9}{|c|}{ LOCATION ATTRIBUTES } \\
\hline \multirow{4}{*}{$\begin{array}{l}\text { D2SCBD } \\
\text { D2CBD }\end{array}$} & \multirow{4}{*}{$\begin{array}{l}\text { Network distance to its district center } \\
\text { Network distance to the center (Bund) }\end{array}$} & & Count & Mean & Std. Dev. & Min & Max & Data Source \\
\hline & & & 40159 & 4.77 & 3.04 & 0.02 & 16.29 & Computed in ArcGIS, with \\
\hline & & & 40159 & 12.62 & 7.48 & 0.03 & 35.11 & Shanghai (2018) shapefile \\
\hline & & Values & Count & $\%$ & $\begin{array}{l}\text { Ave. Price } \\
(¥ / \mathrm{m} 2)\end{array}$ & $\begin{array}{l}\text { Ave. Area } \\
\text { (m2) }\end{array}$ & & \\
\hline \multirow{4}{*}{ RING_X } & \multirow{5}{*}{$\begin{array}{l}\text { Categorical variable, } \\
\text { within which ring road the unit is } \\
\text { located? }\end{array}$} & Ring1 & 9290 & $23.1 \%$ & 81,151 & 88 & & \multirow{19}{*}{$\begin{array}{l}\text { Web scraping from } \\
\text { Lianjia.com, converted to } \\
\text { dummy variables with } \\
\text { Python to dummies library }\end{array}$} \\
\hline & & Ring2 & 9835 & $24.5 \%$ & 63,057 & 79 & & \\
\hline & & Ring3 & 8742 & $21.8 \%$ & 52,356 & 81 & & \\
\hline & & Ring4 & 12292 & $30.6 \%$ & 38,345 & 92 & & \\
\hline \multirow{15}{*}{ CTY_XX } & & BS: Baoshan & 3390 & $8.4 \%$ & 44,159 & 81 & & \\
\hline & \multirow{14}{*}{$\begin{array}{l}\text { Categorical variable, } \\
\text { in which district the unit is located? } \\
\text { The letters XX after CTY_stands for } \\
\text { the district name. }\end{array}$} & $\mathrm{CN}$ : Changning & 2400 & $6.0 \%$ & 70,051 & 83 & & \\
\hline & & FX: Fengxian & 992 & $2.5 \%$ & 24,524 & 95 & & \\
\hline & & HK: Hongkou & 1513 & $3.8 \%$ & 66,210 & 80 & & \\
\hline & & HP: Huangpu & 1267 & $3.2 \%$ & 92,725 & 103 & & \\
\hline & & JA: Jin'an & 964 & $2.4 \%$ & 95,101 & 90 & & \\
\hline & & JD: Jiading & 1662 & $4.1 \%$ & 37,527 & 87 & & \\
\hline & & MH: Minhang & 4806 & $12.0 \%$ & 49,479 & 91 & & \\
\hline & & PD: Pudong & 9389 & $23.4 \%$ & 57,590 & 87 & & \\
\hline & & PT: Putuo & 2941 & $7.3 \%$ & 58,412 & 76 & & \\
\hline & & QP: Qingpu & 678 & $1.7 \%$ & 30,976 & 94 & & \\
\hline & & JS: Jinshan & 2201 & $5.5 \%$ & 36,432 & 100 & & \\
\hline & & XH: Xuhui & 3060 & $7.6 \%$ & 74,879 & 79 & & \\
\hline & & YP: Yangpu & 3091 & $7.7 \%$ & 62,677 & 72 & & \\
\hline & & ZB: Zhabei & 1805 & $4.5 \%$ & 63,647 & 79 & & \\
\hline \multicolumn{9}{|c|}{ NEIGHBORHOOD ATTRIBUTES } \\
\hline & & & Count & Mean & Std. Dev. & Min & Max & Data Source \\
\hline DENSRV & Density of Living Service (thousand $/ \mathrm{k}$ & $\mathrm{km} 2)$ & 40159 & 0.115 & 0.187 & 0 & 3.5 & from Dazhongdianping.com, \\
\hline DENWRK & Density of Office (thousand/km2) & & 40159 & 9.5 & 22.4 & 0 & 573.5 & density calculated in ArcGIS \\
\hline D2MTR & Distance to Metro $(\mathrm{km})$ & & 40159 & 0.8 & 0.7 & 0.01 & 7.8 & \\
\hline A2MTR & Accessibility to Metro & & 40159 & 5.7 & 6.8 & 0 & 46.0 & GaodeMan som distances \\
\hline D2SCH & Distance to School $(\mathrm{km})$ & & 40159 & 2.7 & 2.3 & 0.02 & 11.9 & calculated in Python \\
\hline A2SCH & Accessibility to School & & 40159 & 7.0 & 7.0 & 0 & 29.0 & \\
\hline
\end{tabular}




\begin{tabular}{llllllll} 
S1_GREEN & Subjectively perceived greenness & 40159 & 0.8 & 0.0 & 0.4 & 0.9 & Predicted with ML models \\
S2_WLKBL & Subjectively perceived walkability & 40159 & 0.6 & 0.1 & 0.4 & 0.8 & with physical feature view \\
S3_SAFTY & Subjectively perceived safety & 40159 & 0.7 & 0.1 & 0.3 & 1.0 & indices as independent \\
S4_IMBLT & Subjectively perceived imageability & 40159 & 0.7 & 0.1 & 0.3 & 0.9 & variables extracted from \\
S5_ENCLS & Subjectively perceived enclosure & 40159 & 0.7 & 0.1 & 0.3 & 0.9 & Baidu SVIs \\
S6_CMPLX & Subjectively perceived complexity & 40159 & 0.6 & 0.0 & 0.5 & 0.9 & \\
\hline SUBJECTIVE STREETSCAPE ATTRIBUTES & & & & & & \\
\hline O1_GREEN & Objectively derived greenness & 40159 & 0.4 & 0.1 & 0.0 & 0.8 & Equation derived scores by \\
O2_WALKB & Objectively derived walkability & 40159 & 0.6 & 0.1 & 0.2 & 0.7 & recombining selected \\
O3_SAFTY & Objectively derived safety & 40159 & 0.4 & 0.1 & 0.1 & 0.7 & physical feature view indices \\
O4_IMBLT & Objectively derived imageability & 40159 & 0.6 & 0.1 & 0.0 & 0.9 & 0.7 \\
O5_ENCLS & Objectively derived enclosure & 40159 & 0.6 & 0.0 & 0.1 & &
\end{tabular}

\subsubsection{Model Architecture}

The hedonic modeling comprised four steps. First, as a preliminary test, we added each group of attributes, namely the (1) structural, (2) locational, (3) neighborhood, (4) subjective streetscape scores, and (5) objective streetscape scores into separate OLS models to understand the individual and collaborative contributions of each attribute group. Second, we construct a base model using former three groups of attributes. No streetscape variables were included, and all insignificant variables were removed. Thus we constructed the base model (Model 1). Third, based on Model 1, we added all six subjective scores (Model 2) and all six objective scores (Model 3) separately to examine the different impacts between perceived scores and objectively derived scores. Durbin-Watson results were checked to ensure final models that the autocorrelation effect were not significant. Variance Inflation Factor (VIF) was calculated to examine variables with correlation problems (VIF value $>10$ ), of which less important variables with multicollinearity were removed (Kutner et al., 2004). The global importance of individual variables were tested with Scikit-learn library in Python.

\section{Analysis Results}

\subsection{Descriptive Statistics of the Segmentation}

Using PSPNet pre-trained semantic segmentation algorithm, we quantified the view indices of more than thirty physical features from the 300 training images based on the general formula (1). These view indices became the explanatory variables to predict six subjectively perceived scores (see section 4.2.1) as well as became inputs for the equation derived objective scores ( see Table 1 and section 4.2.2). Among these features (see Table 3), at least about ten elements (e.g. building, sky, tree, curbs, roads, street wall, proportion windows, street furniture's, street lights, and signboard) were conceived to have significant effects on human perception based on urban design literature (Ewing \& Handy, 2009; Ma et al., 2021; F. Zhang et al., 2018; Zhou et al., 2019).

Table 3. Summary of the physical features extracted from the training street view images

\begin{tabular}{|c|c|c|c|c|c|c|c|}
\hline Sort & Feature & Mean Value & Std. Dev. & 21 & column & $0.058 \%$ & $0.513 \%$ \\
\hline 1 & sky & $39.681 \%$ & $17.113 \%$ & 22 & minibike & $0.050 \%$ & $0.291 \%$ \\
\hline 2 & tree & $21.745 \%$ & $17.656 \%$ & 23 & bicycle & $0.040 \%$ & $0.263 \%$ \\
\hline 3 & road & $11.599 \%$ & $6.367 \%$ & 24 & awning & $0.022 \%$ & $0.303 \%$ \\
\hline 4 & building & $11.516 \%$ & $13.828 \%$ & 25 & ashcan & $0.011 \%$ & $0.085 \%$ \\
\hline 5 & plant & $2.147 \%$ & $3.857 \%$ & 26 & windowpane & $0.008 \%$ & $0.324 \%$ \\
\hline
\end{tabular}




\begin{tabular}{|c|c|c|c|c|c|c|c|}
\hline 6 & wall & $2.062 \%$ & $5.368 \%$ & 27 & mountain & $0.007 \%$ & $0.188 \%$ \\
\hline 7 & sidewalk & $1.843 \%$ & $2.615 \%$ & 28 & fountain & $0.003 \%$ & $0.138 \%$ \\
\hline 8 & fence & $1.660 \%$ & $2.799 \%$ & 29 & pier & $0.003 \%$ & $0.083 \%$ \\
\hline 9 & grass & $1.525 \%$ & $2.785 \%$ & 30 & chair & $0.001 \%$ & $0.040 \%$ \\
\hline 10 & car & $1.518 \%$ & $2.582 \%$ & 31 & booth & $0.001 \%$ & $0.052 \%$ \\
\hline 11 & earth & $1.110 \%$ & $2.842 \%$ & 32 & sculpture & $0.001 \%$ & $0.042 \%$ \\
\hline 12 & ceiling & $0.609 \%$ & $5.091 \%$ & 33 & bulletin board & $0.001 \%$ & $0.061 \%$ \\
\hline 13 & railing & $0.346 \%$ & $1.305 \%$ & 34 & lamp & $0.000 \%$ & $0.004 \%$ \\
\hline 14 & bridge & $0.339 \%$ & $2.593 \%$ & 35 & sofa & $0.000 \%$ & $0.001 \%$ \\
\hline 15 & signboard & $0.263 \%$ & $0.875 \%$ & 36 & lake & $0.000 \%$ & $0.000 \%$ \\
\hline 16 & water & $0.255 \%$ & $1.426 \%$ & & & & \\
\hline 17 & van & $0.092 \%$ & $0.674 \%$ & & & & \\
\hline 18 & person & $0.082 \%$ & $0.274 \%$ & & & & \\
\hline 19 & skyscraper & $0.075 \%$ & $0.780 \%$ & & & & \\
\hline 20 & streetlight & $0.061 \%$ & $0.157 \%$ & & & & \\
\hline
\end{tabular}

\subsection{Subjective and Objective Scores and Correlation Analysis}

\subsubsection{Subjective Scores}

The performance of different ML models varied across six perceptual scores. GB outperformed other ML models in Greenness, Walkability and Imageability scores, while SVM was selected to predict Enclosure and Complexity score and RF performed best in predicting Safety score (Table 4). The accuracies of the different subjective score prediction varied. The accuracy rates for predicting Imageability, Greenness and Complexity were slightly higher than that of the rest three, which might be caused by how participants vary in different scene perceptions (F. Zhang et al., 2018). In our study, participants tend to exhibit more similarity in what kind of street view is greener/more imageable $/$ more complex. Another reason might be due to the small sample size (300 images and 45 raters). Therefore, the prediction accuracy was considered acceptable. First, their R2s ranged from 0.48 to 0.51 which indicated that all selected models explained about half of the variance. Second, their MAEs were between 1.2 to 1.51 , indicating that the prediction errors would not offset fitted value away from true scores in the $0-10$ scale.

Table 4. Performance of machine learning algorithms.

\begin{tabular}{|c|c|c|c|c|c|c|c|c|c|c|c|c|}
\hline \multirow[b]{2}{*}{ Model } & \multicolumn{2}{|c|}{ S1_Green } & \multicolumn{2}{|c|}{ S2_Wlkbl } & \multicolumn{2}{|c|}{ S3_Safty } & \multicolumn{2}{|c|}{ S4_Imblt } & \multicolumn{2}{|c|}{ S5_Encls } & \multicolumn{2}{|c|}{ S6_Cmplx } \\
\hline & $\mathbf{R}^{2}$ & MAE & $\mathbf{R}^{2}$ & MAE & $\mathbf{R}^{2}$ & MAE & $\mathbf{R}^{2}$ & MAE & $\mathbf{R}^{2}$ & MAE & $\mathbf{R}^{2}$ & MAE \\
\hline Regression & 0.30 & 1.58 & 0.30 & 1.62 & 0.38 & 1.31 & 0.22 & 1.81 & 0.15 & 1.69 & 0.19 & 1.82 \\
\hline K-Nearest Neighbors (KNN) & 0.27 & 1.54 & 0.39 & 1.50 & 0.34 & 1.31 & 0.07 & 1.81 & 0.36 & 1.70 & 0.21 & 1.77 \\
\hline Support Vector Machine (SVM) & 0.39 & 1.46 & 0.51 & 1.35 & 0.41 & 1.25 & 0.24 & 1.79 & 0.48 & 1.51 & 0.49 & 1.50 \\
\hline Random Forest (RF) & 0.41 & 1.43 & 0.46 & 1.36 & 0.47 & 1.19 & 0.29 & 1.73 & 0.43 & 1.55 & 0.27 & 1.63 \\
\hline Decision Tree (DT) & 0.12 & 1.96 & 0.13 & 1.94 & 0.18 & 1.58 & 0.05 & 2.36 & 0.26 & 2.29 & 0.08 & 2.14 \\
\hline Voting Selection (VS) & 0.35 & 1.53 & 0.36 & 1.55 & 0.43 & 1.26 & 0.26 & 1.78 & 0.35 & 1.60 & 0.31 & 1.60 \\
\hline Gradient Boosting (GB) & 0.49 & 1.39 & 0.48 & 1.33 & 0.47 & 1.21 & 0.51 & 1.62 & 0.41 & 1.52 & 0.14 & 2.01 \\
\hline ADA Boost (ADAB) & 0.31 & 1.57 & 0.48 & 1.33 & 0.26 & 1.53 & 0.20 & 1.84 & 0.41 & 1.52 & 0.32 & 1.63 \\
\hline
\end{tabular}


The best performing models were applied to predict the perceived subjective scores of the six qualities respectively for the 25,276 SVI. Notably, because the objective scores were derived with view indices that ranged from $0-1$, to make these two measurement system results comparable, we also rescaled predicted subjective scores to $0-1$ scale. We then assigned the predicted scores to the property data points by taking the average scores from the SVIs located within the $1 \mathrm{~km}$ radius of the property to represent the average street quality of the surrounding neighborhood (i.e. a 15-minute walking distance for delineating a neighborhood) (Zhou et al., 2019).

In addition, according to urban design theory (Ewing \& Handy, 2009) and statistic inference, not all visual elements extracted from SVIs are significant and relevant in predicting the subjective scores. Therefore, we ranked the Global Importance (GI) of individual visual elements using Tree Based Regressor with Scikit-learn in Python (Chen et al., 2020; Naik et al., 2014). GI computed how much each variable contributes to decreasing the weighted impurity, thus providing the importance score. As a result, view indices of sky, tree, building, car, and road ranked highest in their sum importance (Table 5), which is consistent with prior findings in urban design (Ewing \& Handy, 2009). Fig. 7 reported the feature importance for each subjective score respectively. Surprisingly, several visual elements that have been proved to be important, such as person, sidewalk, signboard, and street furniture, were not in the top ten for predicting Walkability.

Table 5. Features global importance (GI) in predicting six subjective scores

\begin{tabular}{|c|c|c|c|c|c|c|c|c|c|c|c|c|c|c|}
\hline \multirow[b]{2}{*}{ Feature } & \multicolumn{2}{|c|}{ S1_Green } & \multicolumn{2}{|c|}{ S2_Wlkbl } & \multicolumn{2}{|c|}{ S3_Safty } & \multicolumn{2}{|c|}{ S4_Imblt } & \multicolumn{2}{|c|}{ S5_Encls } & \multicolumn{2}{|c|}{ S6_Cmplx } & \multicolumn{2}{|c|}{ Sum Importance } \\
\hline & Imp. Score & Sort & Imp. Score & Sort & Imp. Score & Sort & Imp. Score & Sort & Imp. Score & Sort & Imp. Score & Sort & Sum Score & Sort \\
\hline sky & 0.033 & 8 & 0.183 & 1 & 0.197 & 1 & 0.162 & 1 & 0.492 & 1 & 0.139 & 1 & 1.205 & 1 \\
\hline building & 0.133 & 2 & 0.102 & 3 & 0.108 & 3 & 0.053 & 5 & 0.098 & 2 & 0.099 & 2 & 0.594 & 3 \\
\hline car & 0.057 & 4 & 0.133 & 2 & 0.072 & 4 & 0.038 & 9 & 0.027 & 6 & 0.098 & 3 & 0.423 & 4 \\
\hline road & 0.072 & 3 & 0.037 & 8 & 0.059 & 5 & 0.049 & 6 & 0.046 & 3 & 0.038 & 12 & 0.301 & 5 \\
\hline wall & 0.032 & 9 & 0.030 & 10 & 0.041 & 7 & 0.066 & 4 & 0.021 & 9 & 0.054 & 4 & 0.244 & 6 \\
\hline plant & 0.056 & 5 & 0.050 & 4 & 0.024 & 12 & 0.031 & 10 & 0.033 & 5 & 0.042 & 9 & 0.236 & 7 \\
\hline grass & 0.044 & 7 & 0.029 & 11 & 0.015 & 13 & 0.073 & 3 & 0.022 & 8 & 0.044 & 6 & 0.228 & 8 \\
\hline fence & 0.021 & 13 & 0.050 & 5 & 0.033 & 9 & 0.041 & 7 & 0.015 & 12 & 0.042 & 8 & 0.202 & 9 \\
\hline earth & 0.048 & 6 & 0.048 & 6 & 0.024 & 11 & 0.031 & 11 & 0.017 & 10 & 0.027 & 13 & 0.196 & 10 \\
\hline person & 0.026 & 10 & 0.028 & 13 & 0.036 & 8 & 0.040 & 8 & 0.022 & 7 & 0.038 & 11 & 0.191 & 11 \\
\hline signboard & 0.018 & 14 & 0.034 & 9 & 0.030 & 10 & 0.024 & 16 & 0.015 & 13 & 0.027 & 14 & 0.147 & 13 \\
\hline truck & 0.026 & 11 & 0.017 & 18 & 0.010 & 16 & 0.030 & 12 & 0.013 & 15 & 0.020 & 17 & 0.116 & 14 \\
\hline bicycle & 0.010 & 18 & 0.025 & 16 & 0.005 & 21 & 0.013 & 20 & 0.006 & 23 & 0.046 & 5 & 0.104 & 15 \\
\hline streetlight & 0.016 & 16 & 0.028 & 14 & 0.014 & 15 & 0.016 & 18 & 0.015 & 14 & 0.016 & 19 & 0.104 & 16 \\
\hline railing & 0.017 & 15 & 0.028 & 12 & 0.015 & 14 & 0.010 & 21 & 0.011 & 16 & 0.020 & 18 & 0.102 & 17 \\
\hline chair & 0.010 & 19 & 0.017 & 17 & 0.002 & 25 & 0.030 & 13 & 0.008 & 19 & 0.024 & 15 & 0.091 & 18 \\
\hline minibike & 0.005 & 22 & 0.010 & 21 & 0.005 & 22 & 0.024 & 15 & 0.009 & 18 & 0.021 & 16 & 0.073 & 19 \\
\hline mountain & 0.003 & 23 & 0.015 & 19 & 0.007 & 18 & 0.014 & 19 & 0.010 & 17 & 0.007 & 23 & 0.054 & 20 \\
\hline
\end{tabular}


(a) Top-15 visual elements by sum and individual feature importance scores

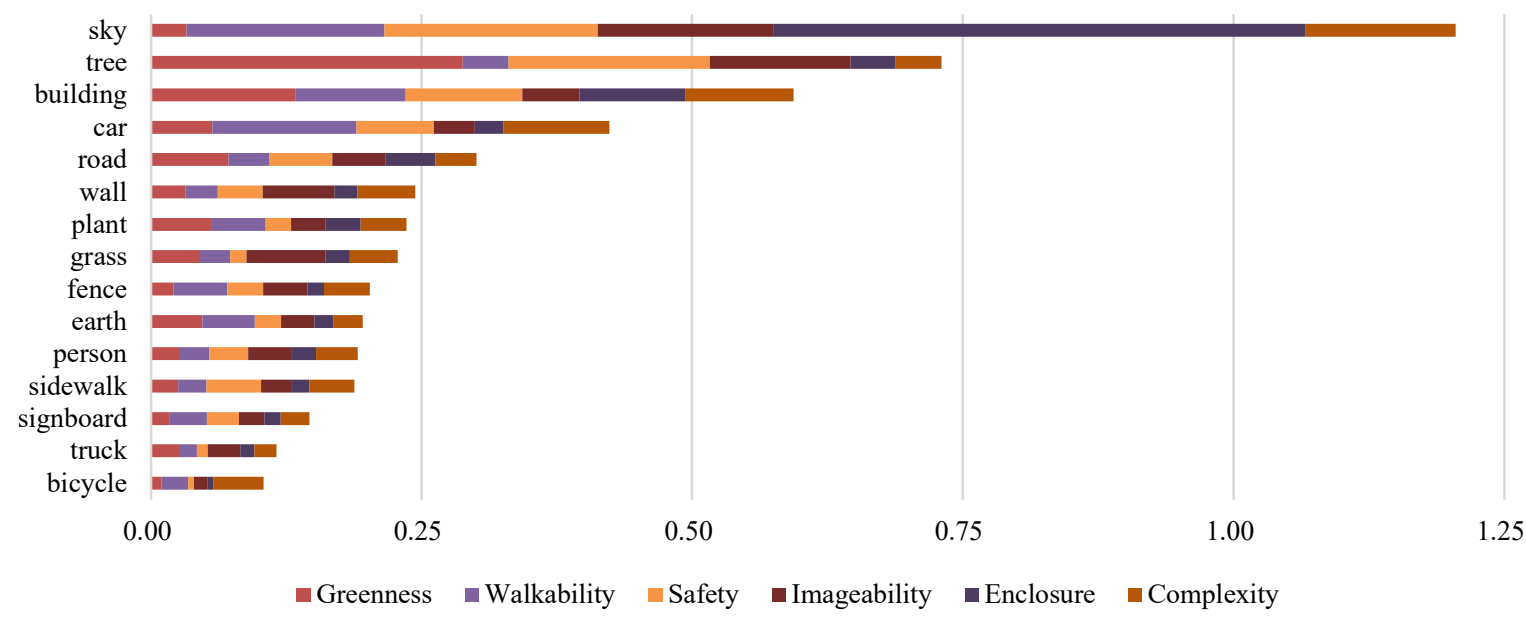

(b) Top-10 visual elements' in predicting 6 subjective qualities respectively

(1) Greenness

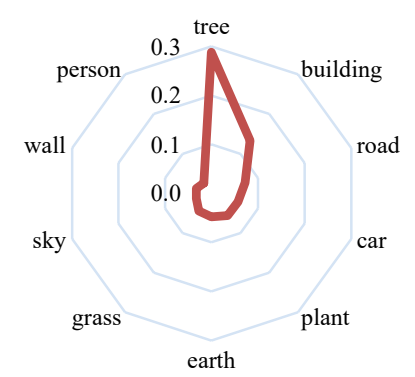

(4) Imageability

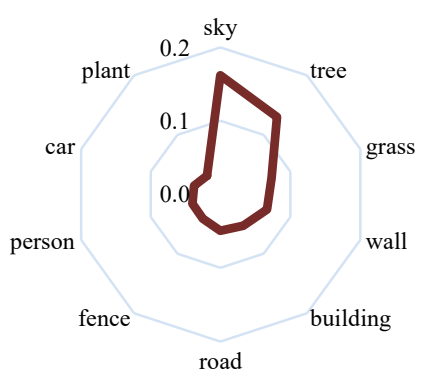

(2) Walkability

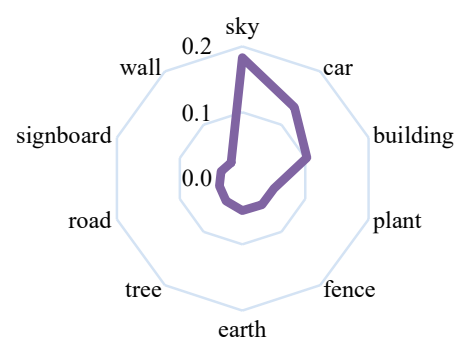

(5) Enclosure

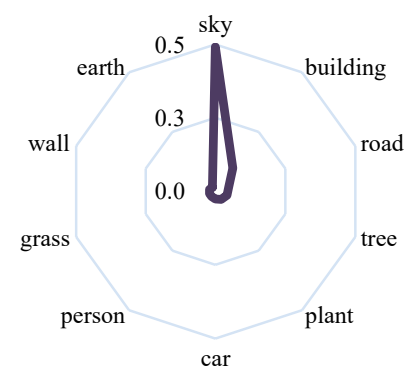

(3) Safety

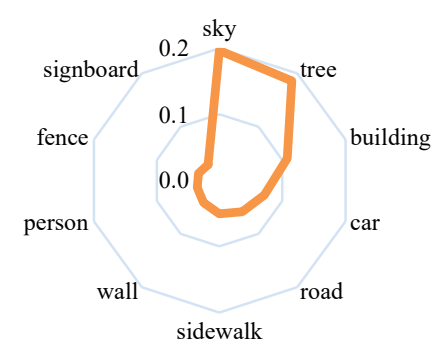

(6) Complexity

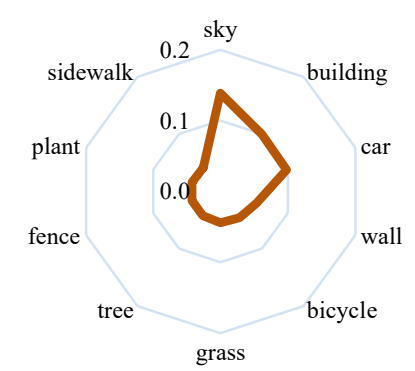

Figure 7. Important features in predicting six subjective scores. (a) Top 15 physical features for each subjective score and their sum importance. (b) Top 10 important visual elements in predicting each subjective score respectively.

\subsubsection{Objective Scores}

The six objective scores were derived by recombining the view indices of selected physical features according to formulas defined in Table 1. According to the formulas, it is clear that there are large differences in the quantity and proportion of dominant visual elements from different locations across Shanghai. Particularly, physical features with vast and ubiquitous existence, such as trees, sky, building and road, directly result in variations in affecting six objective scores. 


\subsubsection{Correlation Analysis for Subjective and Objective Scores Respectively}

Human perceptions are complicated, therefore, intuitively various perceptual qualities could be correlated. A prior study indicated that some pairs of perception measured from SVI were highly correlated, such as "beautiful-wealthy" and "depressing-safe" (F. Zhang et al., 2018). In our study, Pearson correlation analysis was applied to validate the multicollinearity of six scores respectively (Fig. 8).

(a) Subjective scores

\begin{tabular}{lrrrrrr} 
& S1_Green & S2_Walkb & S3_Safty & S4_Imgbl & S5_Encls & S6_Cmplx \\
S1_Green & 1.00 & -0.28 & 0.38 & 0.34 & -0.28 & -0.54 \\
S2_Walkb & -0.28 & 1.00 & 0.54 & 0.51 & 0.91 & 0.82 \\
S3_Safty & 0.38 & 0.54 & 1.00 & 0.82 & 0.61 & 0.40 \\
S4_Imgbl & 0.34 & 0.51 & 0.82 & 1.00 & 0.51 & 0.34 \\
S5_Encls & -0.28 & 0.91 & 0.61 & 0.51 & 1.00 & 0.84 \\
S6_Cmplx & -0.54 & 0.82 & 0.40 & 0.34 & 0.84 & 1.00 \\
\hline
\end{tabular}

(b) Objective scores

\begin{tabular}{lcc|c|r|r|r} 
& O1_Green & O2_Walkb & O3_Safty & O4_Imgbl & O5_Encls & O6_Cmplx \\
\hline O1_Green & 1.00 & 0.14 & 0.12 & -0.84 & 0.14 & 0.21 \\
O2_Walkb & 0.14 & 1.00 & 0.27 & -0.09 & 0.42 & 0.15 \\
O3_Safty & 0.12 & 0.27 & 1.00 & 0.01 & 0.06 & 0.90 \\
O4_Imgbl & -0.84 & -0.09 & 0.01 & 1.00 & 0.08 & -0.12 \\
O5_Encls & 0.14 & 0.42 & 0.06 & 0.08 & 1.00 & -0.11 \\
O6_Cmplx & 0.21 & 0.15 & 0.90 & -0.12 & -0.11 & 1.00
\end{tabular}

Figure 8. Pearson correlation coefficients among the (a) 6 subjective scores and (b) 6 objective scores.

On the one hand, several pairwise coefficients between subjective perceptual qualities have a moderate (between \pm 0.30 and \pm 0.5 ) to high (between \pm 0.50 and \pm 1 ) degree correlation, such as Walkability-Enclosure, Walkability-Complexity, Safety-Imageability, and Enclosure-Complexity. This finding is consistent with literature where enclosure and complexity was positively correlated to walkability (Ewing \& Handy, 2009). It is also intuitively reasonable since these qualities have overlapped definitions, and their operationalized definitions all highly dependent on numbers or view indices of similar visual features such as persons, sky, signboards, and street furniture.

On the other hand, most of the pairwise correlation coefficients between the objective scores have a low (between -.0.3 to 0.3 ) to moderate degree correlation, indicating that the formula-derived measurement of objective perceptions effectively reduced multicollinearity and averted distortion. Only the Safety-Complexity pair has high degree correlation.

The Pearson correlation analysis also helped us to identify that Complexity score should be excluded from hedonic price regression in later section: it was highly correlated to at least one other score for both subjective and objective frameworks. A VIF test in later section also supports this.

\subsubsection{Coherence and Divergence between Subjective and Objective Scores}

First of all, for both predicted and formula derived scores, their data were closed to normal distribution (Fig. 9), indicating the perception qualities fit the most common and natural phenomenon in probability distribution. Second, three qualities, namely Walkability, Imageability and Enclosure see more coherence in their mean value and variance. Third, other three qualities, i.e., Greenness, Safety, and Complexity have more divergence in score distribution. People tent to overstate the perceived qualities since subjective scores' means are all significantly larger than the objective ones. In addition, the variance of objective and subjective Greenness and Enclosure scores indicate that people are less sensitive to the exact number of greenery perceived in a scene indicated by tree view, while they are more sensitive with the perception of enclosure (or openness) than single indicator of sky view. Such divergences between two measurement systems indicated that the underlining mechanism of subjective perception would be quite different from objective formulas. There are unobserved factors cannot be captured by simply summing-up or recombing view indices of selected visual elements. 
(a) Distribution of Subjective Perception Scores
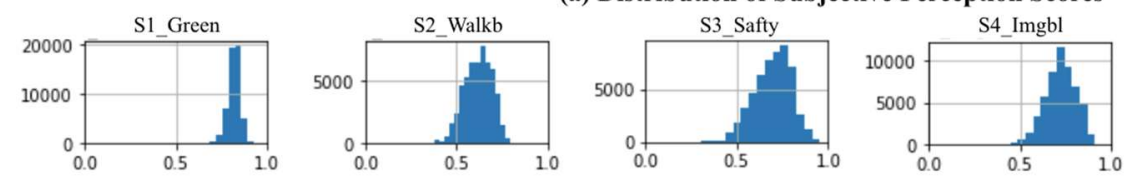

(b) Distribution of Objective Perception Scores
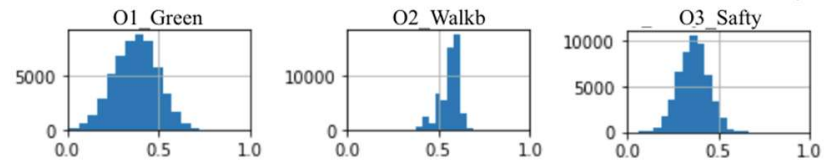
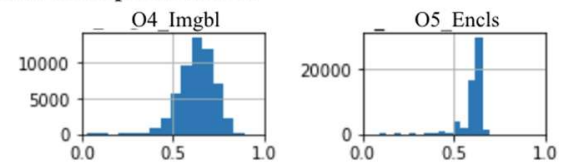
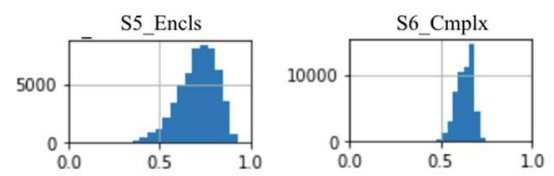

(b) Histogram of six objective scores.

Meanwhile, we randomly selected five SVI samples and provided the segmentation results and perception scores depicted by Fig. 10. The radar chart presents the scores of the six perceptual qualities and is divided into ten levels from 0-1 from the inside out. Clearly, there are larger differences in the Greenness, Complexity, and Safety, while the Walkability, Imageability and Enclosure scores are relatively closer. 

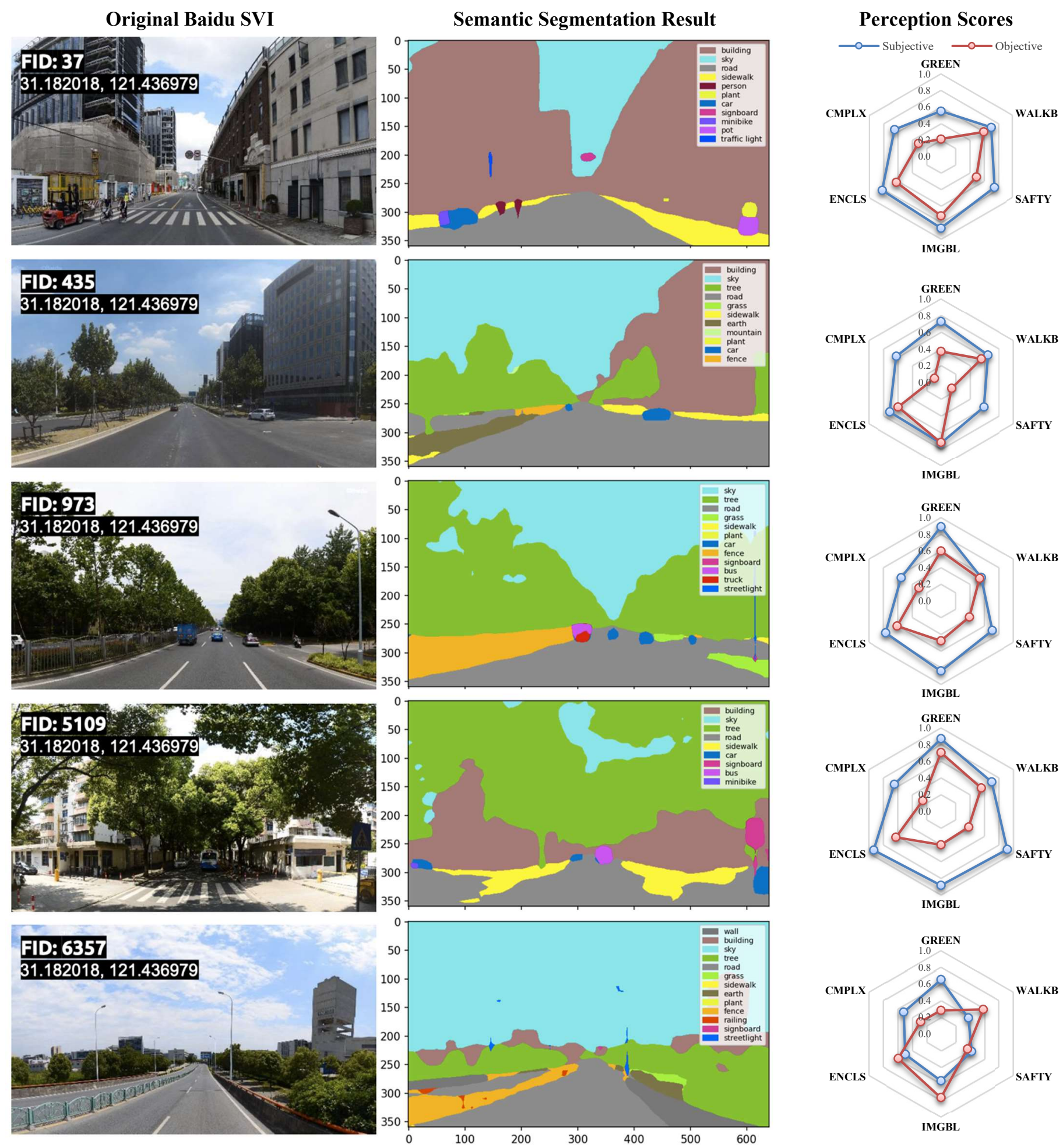

Figure 10. Samples of origin SVI, semantic segmentation result, and the corresponding predicted subjective and derived objective perception scores

\subsection{Hedonic Price Model Selection}


Using coefficient of determination (R2) as a criteria, we first tested the overall importance in explaining housing prices for the five groups of attributes (see Table 6). Their importance were ranked as follows: location $(0.678)>$ neighborhood $(0.556)>$ subjective streetscape scores $(0.322)>$ structural attributes $(0.188)>$ objective streetscape scores $(0.068)$. In addition, all five models passed the F-statistic test $(<0.01)$ which indicated that each attributes group individually play a significant role; their Durbin-Watson values were very close to 2 and did not imply serious autocorrelation effect.

Table 6. Model performance with different groups of attributes

\begin{tabular}{lccccc}
\hline OLS Diagnosis & $\begin{array}{c}\text { Structure } \\
\text { Attributes }\end{array}$ & $\begin{array}{c}\text { Location } \\
\text { Attributes }\end{array}$ & $\begin{array}{c}\text { Neighborhood } \\
\text { Attributes }\end{array}$ & $\begin{array}{c}\text { Subjective } \\
\text { Streetscape Score }\end{array}$ & $\begin{array}{c}\text { Objective } \\
\text { Streetscape Score }\end{array}$ \\
\hline Adjusted R2 & 0.188 & 0.678 & 0.556 & 0.322 & 0.068 \\
Pro (F-statistic) & $0.000^{* * *}$ & $0.000^{* * *}$ & $0.000^{* * *}$ & $0.000^{* * *}$ & $0.000^{* * *}$ \\
Durbin-Watson & 1.986 & 1.999 & 1.9835 & 1.998 & 2.003 \\
\hline
\end{tabular}

We then put all structure, neighborhood and location attributes into a OSL model, and removed insignificant variables such as the structure of the building, numbers of living rooms and kitchens, and some submarket dummy for certain districts. In addition, continuous variables associated with large VIF values (e.g. VIF between 5 to 10) indicated moderate to high correlations, therefore, we removed the less important variable using feature importance test results. For example, within the neighborhood attributes, distance to service variables were removed because they correlated with accessibility measures. Feature importance result showed that accessibility outperform distance measures, and it was intuitively reasonable that the convenience to access a bundle of services was more important than being located close to a particular service. Notably, there was no problem for dummies variables with high VIF. In the end, we formed the base model (model 1) that only consisted of significant structure, location and neighborhood attributes, which explained $78.3 \%$ of the price variances.

Based on the base model 1, we added five subjective (model 2) and objective scores (mode 3) except for Complexity score to the model respectively. Complexity was removed because previously the Pearson correlation analysis indicated that this quality had strong correlation with at least one or two other qualities. Moreover, its VIF test results also indicated its serious multicollinearity issues. Table 7 reported the regression results for the three models with variables' global importance scores and VIFs. Notably, all variables in three models were significant, and most continuous variables' VIFs were smaller than five, which indicated no evidence of strong multicollinearity. Interpretations of the coefficients were based on average values of the three models, with details provided in Appendix.

Table 7. OLS regression results and diagnosis for the three models

\begin{tabular}{|c|c|c|c|c|c|c|c|c|c|c|}
\hline \multirow[t]{2}{*}{ Variable } & \multirow{2}{*}{$\begin{array}{c}\text { Feature } \\
\text { Importance }\end{array}$} & \multicolumn{3}{|c|}{$\begin{array}{c}\text { Model 1 } \\
\text { (Base Model) }\end{array}$} & \multicolumn{3}{|c|}{$\begin{array}{c}\text { Model 2 } \\
\text { (Base }+ \text { Subjective Scores) }\end{array}$} & \multicolumn{3}{|c|}{$\begin{array}{c}\text { Model 3 } \\
\text { (Base }+ \text { Objective Scores) }\end{array}$} \\
\hline & & coef & std err & VIF & coef & std err & VIF & coef & std err & VIF \\
\hline Constant & 1 & $-0.671 * * *$ & 0.106 & 1 & $-0.691 * * *$ & 0.106 & 1 & $-0.770 * * *$ & 0.106 & 1 \\
\hline \multicolumn{11}{|c|}{ Structure Attributes } \\
\hline$F L A R E A$ & 0.831 & $-0.0002 * * *$ & 0.000 & 5.4 & $-0.0002 * * *$ & 0.000 & 5.4 & $\begin{array}{c}- \\
0.0002 * * *\end{array}$ & 0.000 & 5.4 \\
\hline$B E D R M$ & 0.145 & $-0.003 * * *$ & 0.001 & 3 & $-0.002 * * *$ & 0.001 & 3 & $-0.002 * * *$ & 0.001 & 3 \\
\hline BATH & 7.596 & $0.023 * * *$ & 0.001 & 3 & $0.023 * * *$ & 0.001 & 3 & $0.023 * * *$ & 0.001 & 3 \\
\hline CSTRYR & 0.831 & $0.003 * * *$ & 0.000 & 2.3 & $0.003 * * *$ & 0.000 & 2.3 & $0.003 * * *$ & 0.000 & 2.3 \\
\hline ELEVTR & 0.831 & $0.039 * * *$ & 0.001 & 3.5 & $0.040 * * *$ & 0.001 & 3.6 & $0.039 * * *$ & 0.001 & 3.6 \\
\hline
\end{tabular}




\begin{tabular}{|c|c|c|c|c|c|c|c|c|c|c|}
\hline$H G H T$ & 0.831 & $-0.015 * * *$ & 0.001 & 1.2 & $-0.015 * * *$ & 0.001 & 1.2 & $-0.015 * * *$ & 0.001 & 1.2 \\
\hline$T O W E R \_S L A B$ & 0.001 & $-0.064 * * *$ & 0.001 & 2 & $-0.062 * * *$ & 0.001 & 2 & $-0.062 * * *$ & 0.001 & 2 \\
\hline$S T H \_N T H$ & 0.001 & $0.007 * * *$ & 0.001 & 2.1 & $0.007 * * *$ & 0.001 & 2.1 & $0.007 * * *$ & 0.001 & 2.1 \\
\hline REFNDECOR & 0.534 & $0.023 * * *$ & 0.001 & 4.4 & $0.023 * * *$ & 0.001 & 4.7 & $0.023 * * *$ & 0.001 & 4.5 \\
\hline \multicolumn{11}{|c|}{ Location Attributes } \\
\hline$C T Y_{-} F X$ & 2.017 & $-0.167 * * *$ & 0.002 & 2.1 & $-0.164 * * *$ & 0.002 & 2.1 & $-0.172 * * *$ & 0.002 & 2.1 \\
\hline$C T Y_{-} H K$ & 2.136 & $0.018 * * *$ & 0.002 & 1.1 & $0.030 * * *$ & 0.002 & 1.1 & $0.023 * * *$ & 0.002 & 1.1 \\
\hline$C T Y_{-} H P$ & 2.017 & $0.057 * * *$ & 0.002 & 1.3 & $0.069 * * *$ & 0.002 & 1.3 & $0.069 * * *$ & 0.002 & 1.3 \\
\hline$C T Y \_J A$ & 2.017 & $0.065 * * *$ & 0.003 & 1 & $0.073 * * *$ & 0.003 & 1 & $0.075 * * *$ & 0.003 & 1 \\
\hline$C T Y \_J D$ & 2.017 & $-0.060 * * *$ & 0.002 & 1.1 & $-0.059 * * *$ & 0.002 & 1.1 & $-0.059 * * *$ & 0.002 & 1.1 \\
\hline$C T Y \_J S$ & 2.017 & $-0.170 * * *$ & 0.004 & 1.3 & $-0.137 * * *$ & 0.004 & 1.3 & $-0.168 * * *$ & 0.004 & 1.4 \\
\hline$C T Y \_P D$ & 2.017 & $0.027 * * *$ & 0.001 & 1.6 & $0.022 * * *$ & 0.001 & 1.7 & $0.027 * * *$ & 0.001 & 1.7 \\
\hline$C T Y_{-} P T$ & 1.407 & $-0.021 * * *$ & 0.002 & 1.3 & $-0.014 * * *$ & 0.002 & 1.3 & $-0.013 * * *$ & 0.002 & 1.3 \\
\hline$C T Y_{-} Q P$ & 0.831 & $-0.050 * * *$ & 0.003 & 1.2 & $-0.057 * * *$ & 0.003 & 1.3 & $-0.057 * * *$ & 0.003 & 1.3 \\
\hline$C T Y \_S J$ & 0.831 & $-0.050 * * *$ & 0.002 & 1.2 & $-0.046^{* * *}$ & 0.002 & 1.2 & $-0.053 * * *$ & 0.002 & 1.2 \\
\hline$C T Y_{-} Y P$ & 0.831 & $0.033 * * *$ & 0.002 & 1.1 & $0.041 * * *$ & 0.002 & 1.2 & $0.038 * * *$ & 0.002 & 1.2 \\
\hline$C T Y \_Z B$ & 0.831 & $0.022 * * *$ & 0.002 & 1.9 & $0.024 * * *$ & 0.002 & 2 & $0.029 * * *$ & 0.002 & 1.9 \\
\hline LND2CTR & 0.534 & $-0.109 * * *$ & 0.001 & 1.3 & $-0.108 * * *$ & 0.001 & 1.4 & $-0.108^{* * *}$ & 0.001 & 1.4 \\
\hline \multicolumn{11}{|c|}{ Neighborhood Attributes } \\
\hline$L N D E N W R K$ & 0.534 & $0.002 * * *$ & 0.000 & 1.2 & $0.002 * * *$ & 0.000 & 1.2 & $0.002 * * *$ & 0.000 & 1.2 \\
\hline LNDENSRV & 0.534 & $0.003 * * *$ & 0.000 & 1.3 & $0.001 * * *$ & 0.000 & 1.4 & $0.002 * * *$ & 0.000 & 1.3 \\
\hline$L N A 2 M T R$ & 0.534 & $0.021 * * *$ & 0.000 & 2.3 & $0.021 * * *$ & 0.000 & 2.3 & $0.021 * * *$ & 0.000 & 2.3 \\
\hline $\mathrm{LNA2SCH}$ & 0.534 & $0.053 * * *$ & 0.001 & 1.4 & $0.051 * * *$ & 0.001 & 1.4 & $0.052 * * *$ & 0.001 & 1.4 \\
\hline \multicolumn{11}{|c|}{ Subjective Street Scores } \\
\hline S1_GREEN & 0.534 & / & / & / & $-0.327 * * *$ & 0.015 & 2.5 & / & / & / \\
\hline$S 2 \_W A L K B$ & 0.475 & / & / & / & $-0.189 * * *$ & 0.009 & 4.1 & / & / & / \\
\hline$S 4 \_S A F T Y$ & 0.001 & / & / & / & $0.188 * * *$ & 0.010 & 7.7 & / & / & l \\
\hline$S 4 \_I M G B L$ & 0.001 & / & / & / & $0.134 * * *$ & 0.008 & 3.6 & 1 & 1 & / \\
\hline S5_ENCLS & 0.001 & / & / & / & $-0.040 * * *$ & 0.010 & 8.9 & / & / & / \\
\hline \multicolumn{11}{|c|}{ Objective Street Scores } \\
\hline O1_GREEN & 0.534 & / & / & / & / & / & l & $0.034 * * *$ & 0.006 & 4.8 \\
\hline$O 2 \_W A L K B$ & 0.534 & / & / & / & / & / & / & $-0.013 *$ & 0.007 & 1.4 \\
\hline O3_SAFTY & 0.534 & / & / & / & / & / & / & $0.053 * * *$ & 0.005 & 1.2 \\
\hline O4_IMGBL & 0.534 & / & / & / & / & / & / & $-0.074 * * *$ & 0.008 & 4.8 \\
\hline O5_ENCLO & 0.534 & / & l & 1 & 1 & / & 1 & $-0.030 * * *$ & 0.011 & 1.6 \\
\hline \multicolumn{11}{|l|}{ Diagnosis } \\
\hline Adj. $R 2$ & & 0.783 & & & 0.791 & & & 0.787 & & \\
\hline Prob (F-statistic) & & $0 * * *$ & & & $0 * * *$ & & & $0 * * *$ & & \\
\hline Durbin-Watson & & 2.009 & & & 2.007 & & & 2.007 & & \\
\hline No. Observation & & 40,159 & & & 40,159 & & & 40,159 & & \\
\hline
\end{tabular}

$* * *, * *$, and $*$ indicate significance level of $1 \%, 5 \%$ and $10 \%$ respectively

\subsubsection{Location Attributes}

Location attributes were the most dominant, explaining $67.8 \%$ of the price variance. First, centrality to city center represents the level of potential services and have implications on living costs 
such as commuting and education, therefore the distance to city center largely affected sales price. Second, whether or not located in certain districts captured the fix spatial effects that are highly correlated the larger scale neighborhood quality, therefore its price premium incorporated willingness to pay for being closer to school districts and metro stations from neighborhood attributes. In general, with other variables constant, sales price decreased by about $1.1 \%$ with $10 \%$ increase in distance to CBD. Given the average distance $12.6 \mathrm{KM}$ and average house price $57,349 \mathrm{RMB} / \mathrm{m} 2$, per square meter house price decreased by 4,935 RMB if it is 10KM more away from CBD.

Price premium for certain submarkets were identified by submarket dummy variables (e.g. the CTY_XX variables indicating property was within the administrative boundary). For example, on average prices in Jing'an were $6.45 \%$ (or 3,699 RMB/m2) more expensive than the average, while the price in Fengxian was $13.7 \%-17.03 \%$ (or 7,857 to $9767 \mathrm{RMB} / \mathrm{m} 2$ ) cheaper than average.

\subsubsection{Neighborhood Attributes}

Neighborhood attributes included the density of working opportunities (lnDenWrk), the density of living services (lnDenLiv), and accessibility to schools (lnA2Schl) and metro stations (lnA2Metro) were all significant and they explained $55.6 \%$ of the data variance. All neighborhood variables were positively related to house prices, which was consistent with literature (Wen et al., 2017; Y. Zhang \& Dong, 2018). Particularly, the results indicated remarkable price premium of school districts and subway stations: with every five kilometers away from the nearest metro station or important high schools identified by Shanghai government, the house price decreased by $8.8 \%$ and $2.5 \%$ respectively.

\subsubsection{Structure Attributes}

The structural attributes collectively explained $18.8 \%$ of the variance. The signs of their coefficients were consistent with literature. With other variables being constant, apartments with refined interior design were sold $2.3 \%$ (or $1,330 \mathrm{RMB} / \mathrm{m} 2$ ) more expensive. Having south-facing room increased the sales price by $0.7 \%$. In addition, the sales price for apartments with elevators was $3.9 \%$ higher.

\subsubsection{Streetscape Perception Attributes}

Subjective measure significantly outperformed the objective counterparts in explaining house price: the former explained $32.2 \%$ data variance while the latter only explained $6.8 \%$ (see Table 6). Comparing model 2 and model 3, first of all, the impacts of streetscape scores were all significant at 0.01 confidence interval except for the objectively-measured Walkability. Their coefficients were all non-negligible. However, their contributions to the overall goodness-of-fit improvement were minimal, with 0.08 and 0.04 larger R2 values compared to the base model 1 respectively. Their feature importance score ranking indicated that besides Greenness, all other subjective measures had stronger explanation power than the objective counterparts. In addition, subjectively measured Walkability had the largest importance score. 
(a) Python Scikit-learn's feature importance scores

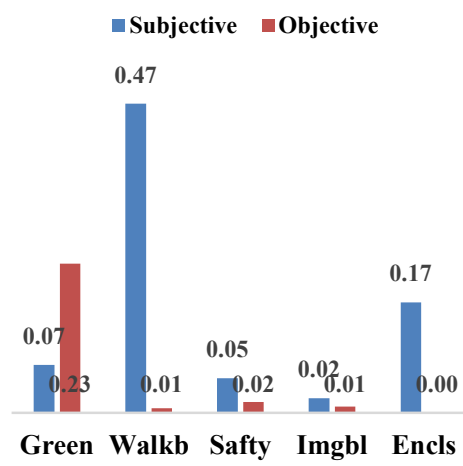

(b) Percentage change if score increases by $10 \%$

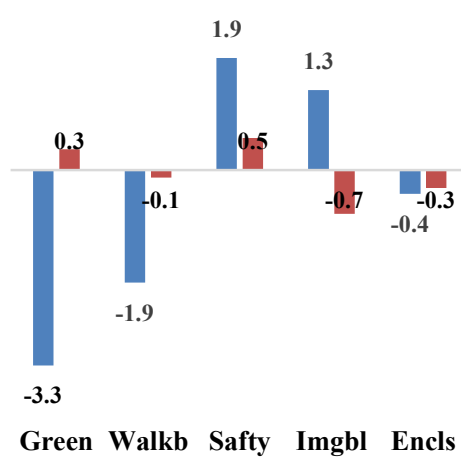

(c) $\mathrm{RMB} / \mathrm{m} 2$ changes if score increases by $10 \%$

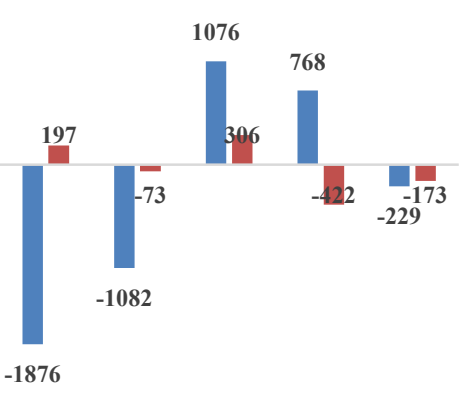

Green Walkb Safty Imgbl Encls

Figure 11. Comparing subjective and objective streetscape scores in (a) global importance ranking, (b) impact on housing price percentage changes and (c) per square meter price change if score increases by $10 \%$

Most importantly, the results indicated coherence as well as large divergence. On one hand, while three perceptual qualities, i.e. Walkability, Safety, and Enclosure implied consistent signs in their subjective and objective measures; the former two also showed large divergence in their coefficient magnitudes (Fig.11b). On the other hand, two subjective and objective scores, i.e. Greenness and Imageability, exhibited opposite signs (Fig.11c). With 10\% increase in Greenness score, the subjective measure was correlated with $-3.3 \%$ (or $-1,876 \mathrm{RMB}$ ) decrease in house prices while objective counterpart was correlated with $0.3 \%$ increase. In addition, for Imageability score, $10 \%$ increase in the subjective score was correlated with $1.3 \%$ increase while objective measure saw a $0.7 \%$ decrease. indicated important future study areas.

\section{Discussion}

\subsection{The Significance of Streetscape Perceptual Qualities}

First, the hedonic estimation implied that both subjectively-measured and formula-derived objective measure of streetscape perception significantly affected house prices in Shanghai. Second, using coefficient of determination as a criteria, the five attribute groups' importance were ranked as follows: locational $>$ neighborhood $>$ subjective streetscape scores $>$ structural $>$ objective streetscape scores. Specifically, except for Greenness score, all other four subjectively measured qualities (i.e. Walkability, Safety, Imageability, and Enclosure) largely outperformed objective counterpart in explaining house prices variance.

However, objective measure also has advantages when the perception definition is clear and its operationalized protocol captures less visual elements. In our case, objectively measured Greenness won the subjective counterpart (Fig. 11a) and the sign of its coefficient was also consistent with large amount of literature (Chen et al., 2020; Fu et al., 2019; Ye et al., 2019; Y. Zhang \& Dong, 2018) that street greenery was positively related to house price. In our study, $10 \%$ increase in the objective Greenness score was related to $0.3 \%$ (or $197 \mathrm{RMB} / \mathrm{m} 2$ ) increase in transaction price, which was smaller in magnitude than a prior study (Chen et al., 2020) where every one percent increase in the GVI increased housing prices by $71 \mathrm{RMB} / \mathrm{m} 2$.

Notably, traditional location and neighborhood attributes, such as being located in certain subcity (district), the accessibility to school, the distance to CBD, and the accessibility to metro stations 
were still among the top six determinants of house prices (see Table 7 feature importance). Three structure variables including decoration, elevator, and number of bathrooms were also among the top ten. However, perceptual qualities such as subjective Walkability was more important than having south facing room, and objective Greenness score and subjective Enclosure score were more important than the floor height in the building, numbers of bedrooms and building age.

While increasing studies with deep learning and SVI focus on single or multiple visual elements' influence, this study implied the non-negligible impacts of more comprehensively measured human perception on house prices. Particularly, objective Greenness, subjective Safety and Imageability scores indicated positive relationship to house prices. In other words, better street environment in these qualities provided non-negligible price premiums to real estate developers, while the cost of investment and maintenance in streetscape was taken care of by the cities. Consider the relatively low financial cost in streetscapes (compared to the house prices in Shanghai), we argued that the economic value of street environment had long been understated or even ignored. Our finding asserted that real estate developers have already obtained benefits from the surrounding street environment but have not provided assistance for facilitating better street scenes such as greening (Ye et al., 2019; Y. Zhang \& Dong, 2018). Hence, city authorities could levy a street environment tax to compensate the public budget invested in designing and maintaining street environment where developers actually enjoyed a premium. The tax amount could be calculated according to the method established in our study if the perception score a residential unit is within the range.

In addition, the findings also advocate urban planners and real estate developers to not merely focus on the micro environment such as the tree canopy and plantation coverage inside the residential blocks, but also on the public domain- the street level that pedestrians and residents can perceive. Street perception scores represent a new metric for street design and urban design guidelines, and can inform urban renewal strategies (Ma et al., 2021). Most importantly, better street perceptual qualities provide improved streetscape aesthetics and appreciation during residents activities and incentivize home buyers willingness to pay.

\subsection{The coherence and divergence between Subjective and Objective Measures}

This study also sheds light on promising future study areas where the coherence and divergence of the two measurements should be further stressed. Specifically, for Greenness and Imageability scores, the subjective and objective measures implied opposite coefficient signs in affecting house prices. While the sign of objective Greenness was positively affecting house prices which was consistent with literature (Fu et al., 2019; Ye et al., 2019), its subjective counterpart exhibited a negative sign. This might possibly due to subjectively-measured Greenness captured more factors than simply the tree canopy. As for Imageability score, the subjective measure indicated a positive impact while its objective counterpart depicted a negative sign. This indicated that simply summing up or recombing visual elements could not comprehensively capture or represent more comprehensively defined perceptual quality.

In general, there are underlining mechanisms that related to the psychological, socialdemographical characteristics of street users that have not been incorporated by view indices or recombination of them, but were significantly affecting home buyers' willingness to pay. Our results suggested that when choosing between subjective and objective measurement, final decision could be made based how familiar (straightforward) the perceptual quality's operationalized definition is to daily street users. Objective measure might outperform subjective one when the connotation of a perceptual quality is self-evident and not complicated, e.g., in our case the Greenness score. Other four dimensions, Walkability, Safety, Imageability, and Enclosure whose concepts were not familiar 
to the average person (Ewing \& Handy, 2009), subjective framework exhibits better performance over objective counterparts.

\subsection{The effectiveness of the integrated big data framework}

Not many research has focused on the economic impact of subjectively measured human-scale perception quality on housing prices at large scale. Prior studies considered streetscape as a determinant were limited to top-down indicators from GIS land use or remote sensing dataset, such as tree canopy area, green area ratio in land use, and the distance to parks. Although emerging studies in this regard focus on human eye-level perception, only one or two objective feature were focused, such as the view index of tree, sky, and building. Our study provided a comprehensive framework for both subjective and objective measures in six important perceptual qualities and took crowdsourcing, opensource, and automated approach. It provides strong generalization capability and can be applied across scales where SVI is available.

\section{Conclusions}

This study proposed a new approach for the urban-scale application to quantify both subjective and objective human-scale streetscape perceptual quality. Built on prior quantitative studies in urban design quality (Ewing \& Clemente, 2013; Ewing \& Handy, 2009; Ma et al., 2021) and emerging applications in deep learning and SVI in urban scene perceptions (Naik et al., 2014; Zhou et al., 2019), we integrated and extended existing frameworks to (1) effectively collect and evaluate both subjectively and objectively- measured perceptions; (2) investigate the coherence and divergence in ML-predicted subjective scores and formula-derived objective scores; and (3) compare the effects on house prices with the two perception measurements taking Shanghai as a case study.

Especially, we investigated the divergence and coherence between subjective and objective measures for six perceptual qualities, i.e., Greenness, Walkability, Safety, Imageability, Enclosure, and Complexity. We quantified their impacts on housing price with a large amount of multisource data including in Shanghai. First, regarding the collective explanatory power within each attributes group, subjective scores explained more variance over structural attributes and objective scores. Second, the percentage increase in sales price attributable to perceived street quality is significant for both subjective and objective measurements. Except for Greenness score, all other subjectively measured qualities outperformed objective counterparts. Particularly, objective Greenness, subjective Safety and Imageability scores positively affected house prices in Shanghai. Objective Greenness was more important than the structure attributes of floor height, numbers of bedrooms and building age that were conventionally conceived importance in HPM. This is the first study comprehensively expanding HPM with both subjectively and objectively measured streetscape qualities. We suggested that city authorities could levy a street environment tax to compensate the public budget invested in street environment where developers secured benefits from a price premium.

Second, this study also sheds light on promising future study areas where the coherence and divergence of the two measurements should be further stressed. Specifically, for Greenness and Imageability scores, the subjective and objective measures implied opposite signs in affecting house prices. On the one hand, there might be mechanisms related to the psychological, socialdemographical characteristics of street users that have not been fully incorporated by view indices or recombination of them, but were significantly affecting home buyers' willingness to pay. On the other hand, when choosing between subjective and objective measurement, final decision could be made based how familiar (straightforward) the perceptual quality's operationalized definition is to daily street users. Objective measure might outperform subjective one when the connotation of a perceptual 
quality is self-evident and not complicated, for example the Greenness. For those concepts were not familiar to the average person, subjective framework exhibits better performance.

There are several limitations. First, the street view scores could be difficult to interpret. Future studies should focus on converting these scores and percentile indices into more actionable urban design guidelines in order to shed light on actionable design interventions that facilitate better streets. Second, since the method seems highly scalable and applicable, applying it to other cities to discover common or divergent impacts of street perception on property values would be highly desirable. Third, data source could be further improved, On one hand, housing data acquisition was limited by the realestate website which indispensably contains missing or biased data, which might lead to bias in model estimation. On the other hand, although the street-level images acquired help us understand the quality of public streets, the impacts of private streets of inner blocks remained unknown due to the lack of SVI data. Fourth, as the consumer's willingness might influence the real estate market and limit the accuracy of the hedonic price model, a detailed survey is required on buyer's attitudes to street quality in housing transactions. Additionally, these potential home buyers could also provide better training sample when ranking the sample SVIs and might provide a very different image in their collective preferences in street environments.

\section{Funding}

This research received Kermit C. \& Janice I. Parsons Scholarship (2019) from City and Regional Planning Department, Cornell University.

\section{Acknowledgements}

We would like to thank the participants who helped to rank SVI perception qualities in the Digital Future Workshop (2020) as well as the sponsor and organizer of the workshop- Prof. Philip YUAN and Tongji University.

\section{Author Contributions}

Conceptualization, W.Qiu. and X.Huang; methodology, W.Qiu.; software, W.Qiu. and X.Li.; validation, W.Qiu.; formal analysis, W.Qiu.; investigation, W.Qiu.; resources, W.Qiu., W.Li., X.Liu. and X.Huang.; data curation, W.Qiu. W.Li. and X.Liu.; writing — original draft preparation, W.Qiu.; writing - review and editing, W.Qiu., W.Li, Z.Zhang and X.Li; visualization, W.Qiu.; supervision, Z.Zhang and X.Li.; project administration, W.Qiu.; funding acquisition, W.Qiu. All authors have read and agreed to the published version of the manuscript."

\section{Appendix}

Table A1

Interpretation of regression coefficients (converted to $\mathrm{RMB} / \mathrm{m} 2$ )

\begin{tabular}{|c|c|c|c|c|c|c|}
\hline & Model1 & Model2 & Model3 & Average & Delta X & Mean X \\
\hline \multicolumn{7}{|c|}{ Structure Attributes } \\
\hline FLAREA & -11.5 & -11.5 & -11.5 & -11.5 & 1 unit change & $85 \mathrm{~m} 2$ \\
\hline BDRM & -154.8 & -114.7 & -137.6 & -135.7 & & 2.1 \\
\hline ВАТН & 1342.0 & 1307.6 & 1307.6 & 1319.0 & & 1.2 \\
\hline CSTRYR & 160.6 & 166.3 & 160.6 & 162.5 & & 1998 \\
\hline ELEVTR & 2248.1 & 2265.3 & 2225.1 & 2246.2 & $\mathrm{Y} / \mathrm{N}(1 / 0)$ & 0.4 \\
\hline HGHT & -843.0 & -860.2 & -854.5 & -852.6 & $\mathrm{Y} / \mathrm{N}(1 / 0)$ & 0.4 \\
\hline TOWER_SLAB & -3641.7 & -3549.9 & -3532.7 & -3574.8 & $\mathrm{Y} / \mathrm{N}(1 / 0)$ & 0.09 \\
\hline
\end{tabular}




\begin{tabular}{|c|c|c|c|c|c|c|}
\hline STH_NTH & 412.9 & 372.8 & 401.4 & 395.7 & $\mathrm{Y} / \mathrm{N}(1 / 0)$ & 0.8 \\
\hline DÉCOR & 1330.5 & 1301.8 & 1313.3 & 1315.2 & $\mathrm{Y} / \mathrm{N}(1 / 0)$ & 0.52 \\
\hline \multicolumn{7}{|c|}{ Location Attributes } \\
\hline CNTY_FX & -9560.1 & -9422.4 & -9864.0 & -9615.5 & $\mathrm{Y} / \mathrm{N}(1 / 0)$ & 0.025 \\
\hline CNTY_HK & 1026.5 & 1726.2 & 1290.4 & 1347.7 & $\mathrm{Y} / \mathrm{N}(1 / 0)$ & 0.038 \\
\hline CNTY_HP & 3280.4 & 3974.3 & 3934.1 & 3729.6 & $\mathrm{Y} / \mathrm{N}(1 / 0)$ & 0.032 \\
\hline CNTY_JA & 3699.0 & 4197.9 & 4278.2 & 4058.4 & $\mathrm{Y} / \mathrm{N}(1 / 0)$ & 0.024 \\
\hline CNTY_JD & -3418.0 & -3395.1 & -3400.8 & -3404.6 & $\mathrm{Y} / \mathrm{N}(1 / 0)$ & 0.041 \\
\hline CNTY_JS & -9766.5 & -7856.8 & -9611.7 & -9078.3 & $\mathrm{Y} / \mathrm{N}(1 / 0)$ & 0.055 \\
\hline CNTY_PD & 1525.5 & 1278.9 & 1548.4 & 1450.9 & $\mathrm{Y} / \mathrm{N}(1 / 0)$ & 0.234 \\
\hline CNTY_PT & -1175.7 & -820.1 & -751.3 & -915.7 & $\mathrm{Y} / \mathrm{N}(1 / 0)$ & 0.073 \\
\hline CNTY_QP & -2873.2 & -3286.1 & -3268.9 & -3142.7 & $\mathrm{Y} / \mathrm{N}(1 / 0)$ & 0.017 \\
\hline CNTY_SJ & -2878.9 & -2615.1 & -3016.6 & -2836.9 & $\mathrm{Y} / \mathrm{N}(1 / 0)$ & 0.055 \\
\hline CNTY_YP & 1892.5 & 2334.1 & 2202.2 & 2142.9 & $\mathrm{Y} / \mathrm{N}(1 / 0)$ & 0.077 \\
\hline CNTY_ZB & 1250.2 & 1382.1 & 1645.9 & 1426.1 & $\mathrm{Y} / \mathrm{N}(1 / 0)$ & 0.045 \\
\hline $\operatorname{lnD2Ctr}$ & -622.8 & -617.1 & -621.1 & -620.3 & $10 \%$ change & $12.62 \mathrm{~km}$ \\
\hline \multicolumn{7}{|c|}{ Neighborhood Attributes } \\
\hline LNDENWRK & 11.5 & 11.5 & 10.3 & 11.1 & $10 \%$ change & $9,500 / \mathrm{km} 2$ \\
\hline INDENSRV & 14.3 & 6.9 & 9.7 & 10.3 & $10 \%$ change & $115 / \mathrm{km} 2$ \\
\hline INA2MTR & 122.7 & 119.3 & 122.7 & 121.6 & $10 \%$ change & 5.7 \\
\hline LNA2SCH & 306.2 & 293.6 & 300.5 & 300.1 & $10 \%$ change & 7 \\
\hline \multicolumn{7}{|c|}{ Subjective Street Perception } \\
\hline S1_GREEN & / & -1876.5 & / & -1876.5 & 0.1 score change & 0.8 \\
\hline S2_WALKB & l & -1081.6 & / & -1081.6 & 0.1 score change & 0.6 \\
\hline S4_SAFTY & / & 1075.9 & / & 1075.9 & 0.1 score change & 0.7 \\
\hline S4_IMGBL & l & 768.5 & / & 768.5 & 0.1 score change & 0.7 \\
\hline S5_ENCLS & l & -228.8 & 1 & -228.8 & 0.1 score change & 0.7 \\
\hline \multicolumn{7}{|c|}{ Objective Street Scores } \\
\hline O1_GREEN & 1 & l & 197.3 & 197.3 & 0.1 score change & 0.4 \\
\hline O2_WALKB & 1 & / & -73.4 & -73.4 & 0.1 score change & 0.6 \\
\hline O3_SAFTY & l & l & 306.2 & 306.2 & 0.1 score change & 0.4 \\
\hline O4_IMGBL & l & I & -422.1 & -422.1 & 0.1 score change & 0.6 \\
\hline O5_ENCLO & 1 & / & -173.2 & -173.2 & 0.1 score change & 0.6 \\
\hline
\end{tabular}

Y: Average Price $57,349 \mathrm{RMB} / \mathrm{m} 2$

\section{Data Availability Statement}

The data presented in this study are available on request from the corresponding author.

\section{Conflicts of Interest}

The authors declare no conflict of interest.

\section{References}

Anderson, S. T., \& West, S. E. (2006). Open space, residential property values, and spatial context. Regional Science and Urban Economics, 36(6), 773-789. https://doi.org/10.1016/j.regsciurbeco.2006.03.007

BAIDU. (2020). Baidu Map API SDK. https://lbsyun.baidu.com/index.php?title=viewstatic 
Bourassa, S. C., Cantoni, E., \& Hoesli, M. (2010). Predicting House Prices with Spatial Dependence: A Comparison of Alternative Methods. Journal of Real Estate Research, 32(2), 139-160.

Brownson, R. C., Chang, J. J., Eyler, A. A., Ainsworth, B. E., Kirtland, K. A., Saelens, B. E., \& Sallis, J. F. (2004). Measuring the Environment for Friendliness Toward Physical Activity: A Comparison of the Reliability of 3 Questionnaires. American Journal of Public Health, 94(3), 473-483. https://doi.org/10.2105/AJPH.94.3.473 Brownson, R. C., Hoehner, C. M., Day, K., Forsyth, A., \& Sallis, J. F. (2009). Measuring the built environment for physical activity: State of the science. American Journal of Preventive Medicine, 36(4 Suppl), S99-123.e12. https://doi.org/10.1016/j.amepre.2009.01.005

Buonanno, P., Montolio, D., \& Raya-vílchez, J. M. (2013). Housing prices and crime perception. Empirical Economics, 45(1), 305-321. http://dx.doi.org.proxy.library.cornell.edu/10.1007/s00181-012-0624-y

Cavailhès, J., Brossard, T., Hilal, M., Joly, D., Tourneux, F.-P., Tritz, C., \& Wavresky, P. (2008). Pricing the Homebuyer's Countryside View. In A. Baranzini, J. Ramirez, C. Schaerer, \& P. Thalmann (Eds.), Hedonic Methods in Housing Markets: Pricing Environmental Amenities and Segregation (pp. 83-99). Springer New York. https://doi.org/10.1007/978-0-387-76815-1_5

Ceccato, V., \& Wilhelmsson, M. (2020). Do crime hot spots affect housing prices? Nordic Journal of Criminology, 21(1), 84-102. https://doi.org/10.1080/2578983X.2019.1662595

Cervero, R., \& Kockelman, K. (1997). Travel demand and the 3Ds: Density, diversity, and design. Transportation Research Part D: Transport and Environment, 2(3), 199-219. https://doi.org/10.1016/S13619209(97)00009-6

Cetintahra, G. E., \& Cubukcu, E. (2015). The influence of environmental aesthetics on economic value of housing: An empirical research on virtual environments. Journal of Housing and the Built Environment, 30(2), 331-340. https://doi.org/10.1007/s10901-014-9413-6

Chen, L., Yao, X., Liu, Y., Zhu, Y., Chen, W., Zhao, X., \& Chi, T. (2020). Measuring Impacts of Urban Environmental Elements on Housing Prices Based on Multisource Data-A Case Study of Shanghai, China. ISPRS International Journal of Geo-Information, 9(2), 106. https://doi.org/10.3390/ijgi9020106

DigitalFUTURES. (2020). DigitalFUTURES WORLD: Manifesto. DigitalFUTURES.World. https://www.digitalfutures.world/manifesto

Donovan, G. H., \& Butry, D. T. (2010). Trees in the city: Valuing street trees in Portland, Oregon. Landscape and Urban Planning, 94(2), 77-83. https://doi.org/10.1016/j.landurbplan.2009.07.019

Dopico, C. (2020, April 20). How to add Baidu Maps to your application without learning Chinese. Medium. https://medium.com/trabe/how-to-add-baidu-maps-to-your-application-without-learning-chinese-

797b095ffcc8

Dubé, J., \& Legros, D. (2014). Spatial econometrics and the hedonic pricing model: What about the temporal dimension? Journal of Property Research, 31(4), 333-359. https://doi.org/10.1080/09599916.2014.913655

Dubey, A., Naik, N., Parikh, D., Raskar, R., \& Hidalgo, C. A. (2016). Deep Learning the City: Quantifying Urban Perception At A Global Scale. ArXiv:1608.01769 [Cs]. http://arxiv.org/abs/1608.01769

Ewing, R., \& Clemente, O. (2013a). Measuring Urban Design: Metrics for Livable Places. Island Press/Center for Resource Economics. https://www.springer.com/gp/book/9781610912099

Ewing, R., \& Clemente, O. (2013b). Measuring Urban Design: Metrics for Livable Places. Island Press.

Ewing, R., \& Handy, S. (2009a). Measuring the unmeasurable: Urban design qualities related to walkability. Journal of Urban Design, 14(1), 65-84.

Ewing, R., \& Handy, S. (2009b). Measuring the Unmeasurable: Urban Design Qualities Related to Walkability. Journal of Urban Design, 14(1), 65-84. https://doi.org/10.1080/13574800802451155

Ewing, R., Handy, S., Brownson, R. C., Clemente, O., \& Winston, E. (2006). Identifying and Measuring Urban Design Qualities Related to Walkability. Journal of Physical Activity \& Health, 3(s1), S223-S240. https://doi.org/10.1123/jpah.3.s1.s223

Fu, X., Jia, T., Zhang, X., Li, S., \& Zhang, Y. (2019). Do street-level scene perceptions affect housing prices in Chinese megacities? An analysis using open access datasets and deep learning. PLOS ONE, 14(5), e0217505. https://doi.org/10.1371/journal.pone.0217505

Griew, P., Hillsdon, M., Foster, C., Coombes, E., Jones, A., \& Wilkinson, P. (2013). Developing and testing a street audit tool using Google Street View to measure environmental supportiveness for physical activity. International Journal of Behavioral Nutrition and Physical Activity, 10(1), 103. https://doi.org/10.1186/14795868-10-103 
Hara, K., Sun, J., Moore, R., Jacobs, D., \& Froehlich, J. (2014). Tohme: Detecting curb ramps in google street view using crowdsourcing, computer vision, and machine learning. Proceedings of the 27th Annual ACM Symposium on User Interface Software and Technology - UIST '14, 189-204. https://doi.org/10.1145/2642918.2647403

He, L., Páez, A., \& Liu, D. (2017). Built environment and violent crime: An environmental audit approach using Google Street View. Computers, Environment and Urban Systems, 66, 83-95. https://doi.org/10.1016/j.compenvurbsys.2017.08.001

Humpel, N., Owen, N., Iverson, D., Leslie, E., \& Bauman, A. (2004). Perceived environment attributes, residential location, and walking for particular purposes. American Journal of Preventive Medicine, 26(2), 119125. https://doi.org/10.1016/j.amepre.2003.10.005

Jackson, L. E. (2003). The relationship of urban design to human health and condition. Landscape and Urban Planning, 64(4), 191-200. https://doi.org/10.1016/S0169-2046(02)00230-X

Jansson, C. (2019). Factors important to street users' perceived safety on a main street. http://urn.kb.se/resolve?urn=urn:nbn:se:kth:diva-260049

Jim, C. Y., \& Chen, W. Y. (2009). Value of scenic views: Hedonic assessment of private housing in Hong Kong. Landscape and Urban Planning, 91(4), 226-234. https://doi.org/10.1016/j.landurbplan.2009.01.009

Kelly, C. M., Wilson, J. S., Baker, E. A., Miller, D. K., \& Schootman, M. (2012). Using Google Street View to audit the built environment: Inter-rater reliability results. Annals of Behavioral Medicine, 45(suppl_1), S108-S112. Kim, E. J., \& Kim, H. (2020). Neighborhood Walkability and Housing Prices: A Correlation Study. Sustainability, 12(2), 593. https://doi.org/10.3390/su12020593

Kim, H., \& Carruthers, J. I. (2015). Environmental Benefits of Green Space: Focusing on the Seoul Metropolitan Area (SSRN Scholarly Paper ID 3511324). Social Science Research Network. https://papers.ssrn.com/abstract=3511324

Kutner, M. H., Nachtsheim, C., \& Neter, J. (2004). Applied Linear Regression Models (4th ed.). McGrawHill/Irwin.

https://books.google.com/books/about/Applied_Linear_Regression_Models.html?id=3_AlAQAAIAAJ

Laaksonen, P., Laaksonen, M., Borisov, P., \& Halkoaho, J. (2006). Measuring image of a city: A qualitative approach with case example. Place Branding, 2(3), 210-219. https://doi.org/10.1057/palgrave.pb.5990058

Larsen, J. E., \& Blair, J. P. (2014). Price effects of surface street traffic on residential property. International Journal of Housing Markets and Analysis. https://doi.org/10.1108/IJHMA-12-2012-0062

Laverne, R. J., \& Winson-Geideman, K. (2003). The influence of trees and landscaping on rental rates at office buildings. Journal of Arboriculture, 29(5), 281-290.

Lee, C., \& Moudon, A. V. (2006). Correlates of Walking for Transportation or Recreation Purposes. Journal of Physical Activity \& Health, 3(s1), S77-S98. https://doi.org/10.1123/jpah.3.s1.s77

Leinberger, C., \& Alfonzo, M. (2012). Walk this way: The economic promise of walkable places in Metropolitan Washington, D.C. https://nyuscholars.nyu.edu/en/publications/walk-this-way-the-economic-promise-ofwalkable-places-in-metropol

Li, X., Cai, B. Y., Qiu, W., Zhao, J., \& Ratti, C. (2019). A novel method for predicting and mapping the occurrence of sun glare using Google Street View. Transportation Research Part C: Emerging Technologies, 106, 132-144. https://doi.org/10.1016/j.trc.2019.07.013

Li, X., Zhang, C., Li, W., Ricard, R., Meng, Q., \& Zhang, W. (2015). Assessing street-level urban greenery using Google Street View and a modified green view index. Urban Forestry \& Urban Greening, 14(3), 675-685. https://doi.org/10.1016/j.ufug.2015.06.006

Lin, L., \& Moudon, A. V. (2010). Objective versus subjective measures of the built environment, which are most effective in capturing associations with walking? Health \& Place, 16(2), 339-348. https://doi.org/10.1016/j.healthplace.2009.11.002

Lynch, K. (1960). The Image of the City (Vol. 11). The MIT Press. https://mitpress.mit.edu/books/image-city Ma, X., Ma, C., Wu, C., Xi, Y., Yang, R., Peng, N., Zhang, C., \& Ren, F. (2021). Measuring human perceptions of streetscapes to better inform urban renewal: A perspective of scene semantic parsing. Cities, 110, 103086. https://doi.org/10.1016/j.cities.2020.103086

McCluskey, J. J., \& Rausser, G. C. (2001). Estimation of Perceived Risk and Its Effect on Property Values. Land Economics, 77(1), 42-55. https://doi.org/10.2307/3146979

Mehta, V. (2014). Evaluating Public Space. Journal of Urban Design, 19(1), 53-88. https://doi.org/10.1080/13574809.2013.854698 
Microsoft. (2005). TrueSkillTM Ranking System. Microsoft Research. https://www.microsoft.com/enus/research/project/trueskill-ranking-system/

Minka, T., Cleven, R., \& Zaykov, Y. (2018). TrueSkill 2: An improved Bayesian skill rating system. https://www.microsoft.com/en-us/research/publication/trueskill-2-improved-bayesian-skill-rating-

system/

Naik, N., Philipoom, J., Raskar, R., \& Hidalgo, C. (2014a). Streetscore-Predicting the Perceived Safety of One Million Streetscapes. 2014 IEEE Conference on Computer Vision and Pattern Recognition Workshops, 793-799. https://doi.org/10.1109/CVPRW.2014.121

Naik, N., Philipoom, J., Raskar, R., \& Hidalgo, C. (2014b). Streetscore-Predicting the Perceived Safety of One Million Streetscapes. 779-785. https://www.cvfoundation.org/openaccess/content_cvpr_workshops_2014/W20/html/Naik_Streetscore_-

_Predicting_2014_CVPR_paper.html

Naik, N., Raskar, R., \& Hidalgo, C. A. (2016). Cities Are Physical Too: Using Computer Vision to Measure the Quality and Impact of Urban Appearance. American Economic Review, 106(5), 128-132. https://doi.org/10.1257/aer.p20161030

Nasar, J. L. (1990). The Evaluative Image of the City. Journal of the American Planning Association, 56(1), 4153. https://doi.org/10.1080/01944369008975742

NYU, UN Habitat, \& Lincoln Institute. (2016). Atlas of Urban Expansion-Shanghai, Shanghai. Atlas of Urban Expansion. http://www.atlasofurbanexpansion.org/cities/view/Shanghai_Shanghai

Nyunt, M. S. Z., Shuvo, F. K., Eng, J. Y., Yap, K. B., Scherer, S., Hee, L. M., Chan, S. P., \& Ng, T. P. (2015). Objective and subjective measures of neighborhood environment (NE): Relationships with transportation physical activity among older persons. International Journal of Behavioral Nutrition and Physical Activity, 12(1), 108. https://doi.org/10.1186/s12966-015-0276-3

Orland, B., Vining, J., \& Ebreo, A. (1992). The Effect of Street Trees on Perceived Values of Residential Property. Environment and Behavior, 24(3), 298-325. https://doi.org/10.1177/0013916592243002

Pandit, R., Polyakov, M., \& Sadler, R. (2014). Valuing public and private urban tree canopy cover. Australian Journal of Agricultural and Resource Economics, 58(3), 453-470. https://doi.org/10.1111/1467-8489.12037 Pikora, T., Giles-Corti, B., Bull, F., Jamrozik, K., \& Donovan, R. (2003). Developing a framework for assessment of the environmental determinants of walking and cycling. Social Science \& Medicine, 56(8), 1693-1703. https://doi.org/10.1016/S0277-9536(02)00163-6

Qiu, W., Huang, X., \& Li, X. (2019). Apply Computer Vision and Machine Learning to Measures Human Perception of Street Design Quality: Taking Shanghai Pudong District as an example. 2019 ACSP 59th Annual Conference, Greenville, SC.

Quercia, D., O'Hare, N. K., \& Cramer, H. (2014). Aesthetic capital: What makes london look beautiful, quiet, and happy? Proceedings of the 17th ACM Conference on Computer Supported Cooperative Work \& Social Computing, 945-955. https://doi.org/10.1145/2531602.2531613

Rosen, S. (1974). Hedonic Prices and Implicit Markets: Product Differentiation in Pure Competition. Journal of Political Economy, 82(1), 34-55. JSTOR.

Rundle, A. G., Bader, M. D. M., Richards, C. A., Neckerman, K. M., \& Teitler, J. O. (2011). Using Google Street View to Audit Neighborhood Environments. American Journal of Preventive Medicine, 40(1), 94-100. https://doi.org/10.1016/j.amepre.2010.09.034

Salazar Miranda, A., Fan, Z., Duarte, F., \& Ratti, C. (2021). Desirable streets: Using deviations in pedestrian trajectories to measure the value of the built environment. Computers, Environment and Urban Systems, 101563. https://doi.org/10.1016/j.compenvurbsys.2020.101563

Salesses, P., Schechtner, K., \& Hidalgo, C. A. (2013). The Collaborative Image of The City: Mapping the Inequality of Urban Perception. PLOS ONE, 8(7), e68400. https://doi.org/10.1371/journal.pone.0068400 Seiferling, I., Naik, N., Ratti, C., \& Proulx, R. (2017). Green streets- Quantifying and mapping urban trees with street-level imagery and computer vision. Landscape and Urban Planning, 165, 93-101.

Wen, H., Xiao, Y., \& Zhang, L. (2017). School district, education quality, and housing price: Evidence from a natural experiment in Hangzhou, China. Cities, 66, 72-80. https://doi.org/10.1016/j.cities.2017.03.008

Wikipedia. (2020). Lianjia. https://en.wikipedia.org/w/index.php?title=Lianjia\&oldid=993933239 
Willis, K. G., Powe, N. A., \& Garrod, G. D. (2005). Estimating the Value of Improved Street Lighting: A Factor Analytical Discrete Choice Approach. Urban Studies, 42(12), 2289-2303. https://doi.org/10.1080/00420980500332106

Yang, J., Zhao, L., Mcbride, J., \& Gong, P. (2009). Can you see green? Assessing the visibility of urban forests in cities. Landscape and Urban Planning, 91(2), 97-104. https://doi.org/10.1016/j.landurbplan.2008.12.004 Ye, Y., Xie, H., Fang, J., Jiang, H., \& Wang, D. (2019). Daily Accessed Street Greenery and Housing Price: Measuring Economic Performance of Human-Scale Streetscapes via New Urban Data. Sustainability, 11(6), 1741. https://doi.org/10.3390/su11061741

Yin, L., Cheng, Q., Wang, Z., \& Shao, Z. (2015). 'Big data' for pedestrian volume: Exploring the use of Google Street View images for pedestrian counts. Applied Geography, 63, 337-345. https://doi.org/10.1016/j.apgeog.2015.07.010

Yin, L., \& Wang, Z. (2016). Measuring visual enclosure for street walkability: Using machine learning algorithms and Google Street View imagery. Applied Geography, 76, 147-153. https://doi.org/10.1016/j.apgeog.2016.09.024

Zeng, L., Lu, J., Li, W., \& Li, Y. (2018). A fast approach for large-scale Sky View Factor estimation using street view images. Building and Environment, 135, 74-84. https://doi.org/10.1016/j.buildenv.2018.03.009

Zhang, F., Zhou, B., Liu, L., Liu, Y., Fung, H. H., Lin, H., \& Ratti, C. (2018). Measuring human perceptions of a large-scale urban region using machine learning. Landscape and Urban Planning, 180, 148-160. https://doi.org/10.1016/j.landurbplan.2018.08.020

Zhang, Y., \& Dong, R. (2018). Impacts of Street-Visible Greenery on Housing Prices: Evidence from a Hedonic Price Model and a Massive Street View Image Dataset in Beijing. ISPRS International Journal of GeoInformation, 7(3), 104. https://doi.org/10.3390/ijgi7030104

Zhao, H., Shi, J., Qi, X., Wang, X., \& Jia, J. (2016). Pyramid Scene Parsing Network. https://arxiv.org/abs/1612.01105v2

Zhou, H., He, S., Cai, Y., Wang, M., \& Su, S. (2019). Social inequalities in neighborhood visual walkability: Using street view imagery and deep learning technologies to facilitate healthy city planning. Sustainable Cities and Society, 50, 101605. https://doi.org/10.1016/j.scs.2019.101605 